\title{
TITLE:
}

\section{Interface from Transaction Cost Approach}

$\operatorname{AUTHOR}(\mathrm{S})$ :

Suematsu, Chihiro; Makabenta-Ikeda, Maria

\section{CITATION:}

Suematsu, Chihiro ...[et al]. Interface from Transaction Cost Approach. 京都大学大学院経 済学研究科Working Paper 2006, 84

ISSUE DATE:

2006-06

URL:

http://hdl.handle.net/2433/26704

RIGHT: 


\title{
Interface from Transaction Cost Approach
}

\author{
Chihiro Suematsu \\ (Kyoto University) \\ Maria Makabenta-Ikeda \\ (Kyoto College of Graduate Studies for Informatics)
}

June, 2006 


\title{
Interface from Transaction Cost Approach*
}

\author{
Chihiro Suematsu \\ (Kyoto University) \\ Maria Makabenta-Ikeda \\ (Kyoto College of Graduate Studies for Informatics)
}

June 28, 2006

\begin{abstract}
Two decades ago, Oliver E. Williamson defined a transaction as the transfer of a good or service across a technologically separable interface, and yet the characteristics of interfaces have not been studied by transaction cost economics researchers. Another related concept is that of the module which is commonly defined as a unit sharing multiple interfaces in order to interact, integrate and combine, or be substituted, redeployed, transferred, and suplanted; but the term interface is referred to in very few studies of modularity. The purpose of this research is to describe and understand further the transaction mechanism related to the notion of interface (transaction interface). The analysis of transaction costs, institutions, and organizations from the perspective of the interface is proposed. We believe that the importance of studying interfaces has been increasing with the proliferation of economic activities over the Internet. Governance mechanisms existing beyond markets and organizations may likewise be explained by focusing on various interface aspects.
\end{abstract}

Keywords: transaction cost, interface, transaction, module, organizational economics

\footnotetext{
* Working Paper No. 84, Graduate School of Economics, Kyoto University

- Corresponding author: Graduate School of Economics, Yoshida-Hommachi, Sakyo-ku, Kyoto 606-8501 eMail: suematsu@econ.kyoto-u.ac.jp
} 


\section{Introduction}

While most neoclassical economists focused during the early part of the twentieth century on modeling production costs in a general equilibrium framework using Cobb-Douglas production functions, Coase (1937) ${ }^{\mathrm{i}}$ came up with his seminal ideas on the nature of the firm using partial equilibrium analysis. He cited the importance of systems attributing transaction cost as one of the key concepts in economic analysis. His ideas together with Williamson $(1985)^{\text {ii }}$ built the foundation of what is now known as transaction cost economics with empirical works in comparative institutional analysis and management. Transaction cost economics is also considered to have extensive influence on industrial organization

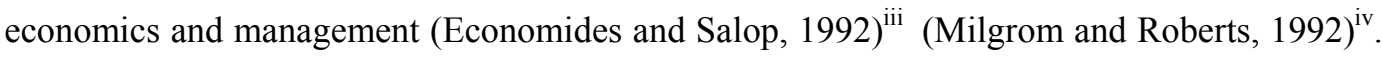
The same can be said of contract theory which analyzes economic behavior of agents in resource utilization against the backdrop of tradeoffs among various transaction costs such as information, bargaining, monitoring, and agency costs. Williamson (1985) had defined a transaction as the transfer of a good or service across a technologically separable interface, and yet transaction cost economics researchers continue to ignore the significance of interfaces.

A related concept is that of modularity. Entities with defined interfaces are called "modules" and modularity as a structure of systems has been researched in various fields after the IT industry's success widely attributed to the deployment of modularity in industry and product design structures. A module is commonly defined as a unit sharing multiple interfaces to interact, integrate and combine; but the term interface is referred to in very few studies of modularity. Modularity existing beyond the boundary of organization can be explained by analyzing its various interface aspects. As a general systems concept, modularity has a strong affinity with organization theory and has broad implications vis-à-vis outsourcing and contract manufacturing, the network organization structure in Silicon Valley (Daft and Lewin, 1993) ${ }^{\mathrm{v}}$ (Sanchez, 1995) $^{\mathrm{vi}}$ (Ashkenas, Ulrich, Jick, and Kirr, 1995) ${ }^{\mathrm{vii}}$ (Snow, Miles, and Coleman, 1992) ${ }^{\text {viii }}$ and so forth. In some studies, findings show that almost all systems are, to some extent, modular (Schilling, 2000) ${ }^{\text {ix }}$. Without question, automobile manufactures have been using numerous modular components. However, many researchers such as Clark \& Fujimoto $(1990)^{\mathrm{x}}$ focus on their non-modular coherent structure as the most important success factor of these consumer durables. There is a significant need for issues related to complexity to be further analyzed.

In spite of its increasing popularity, however, there exists no accurate definition of modularity 
yet. Even in the most accepted definition which states that a module is a unit with elements that are "relatively" tightly and coherently coupled/connected inside and "relatively" loosely and weakly outside, that relativity is still shrouded with ambiguity and needs to be expounded further. Substantial transaction costs accrue as interfaces are established and used, and investigating the transaction costs mechanism requires careful study of the interfaces involved.

We hereby focus on the common characteristic observed by researchers of both transaction cost economics and modularity which is substitutability, transferability, fungibility, or redeployability, and propose to introduce the notion of interface (transaction interface) to further analyze these issues. Interface is defined as the parameters/media through which transactions are made between two entities. Our purpose is to develop a model for understanding the mechanism of interfaces from the transaction cost approach. In today's network era, growth is heavily determined by the ability or capacity of an entity (any individual, organization or economy) to absorb, utilize and exchange resources through interfaces that play important roles. We believe that the need to study interfaces has been increasing especially with the proliferation of economic activities over the Internet which not only allows high-speed transmission of information but also facilitates collaboration between the entities involved in a transaction. 


\section{Previous Researches}

This research is founded on the concepts developed in the fields of transaction cost economics and modularity. We benefited from the significant works in these areas which we consider as the forerunners of interface economics.

\section{TRANSACTION COST}

After Coase (1937) established a niche for the concept of transaction costs in economics, Williamson and several other scholars explored the concept further. "Transaction costs are arguably the most important set of prices in an economy" (Benham and Benham, 2000) ${ }^{\mathrm{xi}}$. "(I)n the modern world, it would be difficult to find a rich country where transaction costs sum up to less than half of national income" (Cheung, 1988). Wallis \& North (1986) (iii $^{\text {xii }}$ estimated the overall size of the transaction sector in 1970 as about 45 percent of the U.S. gross national product. The concept of transaction costs is not only crucial in economics, but also is considered as the backbone for theoretical explanations of international organizations $\left(\right.$ Sandler and Cauley, 1977) ${ }^{\mathrm{xiv}}$ (Keohane, 1984) $^{\mathrm{xv}}$ (Yarbrough and Yarbrough, 1990) $^{\mathrm{xvi}}$ (Downs and Rocke, 1995) ${ }^{\mathrm{xvii}}$ (Kang, 1995) ${ }^{\mathrm{xviii}}$ (Lake, 1999) ${ }^{\mathrm{xix}}$ (Moravcsik, 1999) $^{\mathrm{xx}}$ (Wallander, 2000) $^{\mathrm{xxi}}(\text { Weber, 2000) })^{\mathrm{xxii}}$ as quoted in (Lipson, 2004) ${ }^{\mathrm{xxiii}}$.

The definition of transaction costs still varies among different fields and there have been very few empirical studies on comparative measurement or measurement itself (Benham and

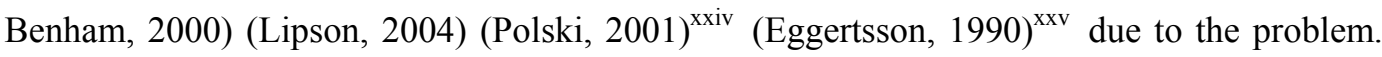
Dahlstrom \& Nygaard (2005) $)^{\mathrm{xxvi}}$ warn that transaction cost economics "cannot survive another 30 years without empirical measurement of the key theoretical element, namely, "transaction costs."

Coase defines transaction costs as "the costs of using the price mechanism, which includes the costs of discovering relevant prices, and negotiating and concluding contracts"(Coase, 1937) and "the costs of resources utilized for the creation, maintenance, use, and change of institutions and organizations" which include the costs of defining and measuring resources or claims, the costs of utilizing and enforcing the rights specified, and the costs of information, negotiation, and enforcement (Coase, 1960) ${ }^{\mathrm{xxvii}}$.

According to Williamson (1985), transaction costs include the ex ante costs of drafting, negotiating, and safeguarding an agreement, and the ex post costs of haggling, costs of governance, and bonding costs to secure commitments. Alchian \& Woodward $(1988)^{\text {xxviii }}$ 
asserted that Williamson's focus is mainly on contractual issues such as administrating, informing, monitoring, and enforcing contracts, not on market exchange issues such as finding other people, inspecting goods, seeking agreeable terms, and writing exchange agreements. They define it as "the costs incurred in exchange transactions involving the transfer of property rights and contracting transactions involving negotiating and enforcing promises about performance."

Arrow (1969) refers to transaction costs as "the costs of running the economic system." The following is a running list of definitive statements on transaction costs in various studies.

-"the costs of processing and conveying information, coordinating, purchasing, marketing, advertising, selling, handling legal matters, shipping, and managing and supervising." (Wallis and North, 1986)

-"those costs associated with 'greasing markets,' including the costs of obtaining information, monitoring behavior, compensating intermediaries, and enforcing contracts." (Davis, 1986)

-"the cost of arranging a contract ex ante and monitoring it ex post, as opposed to production costs, which are the costs of executing a contract." (Matthews, 1986) ${ }^{\mathrm{xxx}}$

- "all the costs which do not exist in a Robinson Crusoe economy" as it is difficult to separate one type of transaction cost from another. (Cheung, 1988)

-"the costs associated with the transfer, capture, and protection of rights." (Barzel, $1989)^{\mathrm{xxxi}}$

-"the costs that arise when individuals exchange ownership rights to economic assets and enforce their exclusive rights." (Eggertsson, 1990)

-"those (the costs) involved in the transfer of goods and services from one operating unit to another...they usually involve the transfer of property rights and are defined in contractual terms." (Chandler and Hikino, 1990)

-"the costs of defining and measuring resources or claims, plus the costs of utilizing and enforcing the rights specified" when considered in relation to existing property and 
contract rights; and, quoting Coase (1960), the definition includes "costs of information, negotiation, and enforcement" when applied to the transfer of existing property rights and the establishment or transfer of contract rights between individuals (or legal entities)." (Furubotn and Richter, 1997)

-"the costs of running the systems: the costs of coordinating and of motivating." (Milgrom and Roberts, 1992)

-"the sum of the costs associated with engaging in exchange and contracting activities, which are distinct from the costs of production" (Polski, 2001). The transaction costs at plant, however, are not easily separable from production costs considering that what Eggertsson (1990) designates the costs of production in the neoclassical model are not well defined.

-"the costs of acquiring and handling the information about the quality of inputs, the relevant prices, the supplier's reputation, and so on.” (Vannoni, 2002) ${ }^{\mathrm{xxxv}}$

The list above indicates that the costs for contract and information are included in all the definitions above, but ordering/invoicing, clearing/settlement, transportation, switching activities such as training/education, integration and management, infrastructure and media have not been clearly specified by any of the above-mentioned researchers. Polski (2001) pointed out "North $\left(1990^{\text {xxxi }}, 1997\right)$, Wallis and North (1986), and Williamson $(1985,1999)$ have all argued that transaction costs are embedded in layers of governance structures," so that it is not easy to separate and define transaction costs explicitly.

Clearing and settlement, however, are considered important procedural components of an exchange particularly those involving financial or cash flow transactions. On the other hand, ordering tend to have a non-specific nature because it is deemed as a kind of contract. Contracts essentially designate the conditions of exchange, however, these do not necessarily include the execution orders of the exchange that are clearly based on the occurrence of ordering and invoicing. In this study, ordering and invoicing are specified separately from the contract and are considered elements of transaction costs.

The complex nature of transportation has proved to be challenging to previous researchers because physical flow seems to be separable from information flow. Cheung (1988) excluded the transportation costs and production costs from transaction costs because he considered 
these to be physical processes while Wallis \& North (1986) included the transportation costs as "shipping costs". If we define an exchange as a transfer of goods or services and related information, it stands to reason that a transaction may be defined as an exchange with a corresponding order of sequential activities required to complete the exchange. Based on this specification, our concept of transaction includes transportation by definition. Moreover, it attributes transportation cost to "site specificity" (Williamson, 1985) which plays an important role in transaction cost economics.

In addition, information flow in transportation such as receiving, tracking, expediting, data processing, accounting, etc. are quite often embedded in the transportation itself and not separable. The costs incurred in moving cargo or changing the location coordinates of plant infrastructure, whether through manual or mechanical means within organization, are most often reflected in management costs (Chandler and Hikino, 1990). In some instances, the physical transfer or logistical movement of a good signifies the completion of an exchange and in that case, transportation is considered an information flow as well. Physical flow of money is a good example. Some transportation costs are inseparable from the well-accepted notion of "transaction costs". Furthermore, it is an important cost factor to be considered with regard to the decision of executing transactions and should be given careful consideration.

The switching costs related to such activities as training/education, management and business process integration for a newly deployed good/service influence decisions on transaction execution as a cost factor and, for that reason, need careful analysis as well. Furubotn and Richter (1997) called attention to political transaction costs and managerial transaction costs along with market transaction costs. Political transaction costs include "the costs of setting up, maintaining and changing a system's formal and informal political organization" and "the costs of running a polity". Managerial transaction costs reduce "the costs of setting up, maintaining or changing an organizational design" and "the costs of running an organization." Williamson (1985) also included accounting and control systems as well as monitoring systems. The switching cost is considered to be an internal enforcement cost while costs incurred in enforcing compliance measures involving external entities are widely-accepted to be included in transaction costs. Therefore, costs of this nature should be included in the transaction costs.

Infrastructure and media are indispensable for the transfer of information and physical objects to occur. For instance, contracts may be sent via the post under the pay per use setup. Alternatively, information can be exchanged via the Internet, by using a monthly leased 
dedicated line, or even by building one's own communication line or network. Investing in the acquisition of telecom equipment such as digital telephone switches, routers, servers, etc. is often required. In the case of pay per use, it is easily measurable as a transaction cost but the allocation of infrastructure cost, such as durable goods and equipment as well as media cost are embedded and not easily distinguishable. The same can be said of management costs which are highly intangible and are most often dealt with in conventional accounting systems as part of overhead or as a bulk of miscellaneous costs. Most of these costs are often embedded by nature but involve significant friction factors that merit careful analysis.

So we recognize transaction costs as all the costs incurred needed to complete exchange related with the transfer of a physical object ${ }^{1}$ and information, including the costs of ordering/invoicing, clearing/settlement, transportation, switching activities such as training/education, integration, and related management, and infrastructure and media. Money transfer is divided into and included in physical and information transfer (settlement and clearing, respectively).

\section{MODULARITY}

With the discussion of modularity in relation to product design and as a key structural mechanism that brought about growth and prosperity to the IT industry which most adopted it, modularity increasingly became a popular topic as an analytical approach to formulate ways to deal efficiently with the architecture and production of complex products and processes. However, modularity should not be mistaken as a newly developed concept due to recent phenomenon. Baldwin \& Clark (1997) ${ }^{\mathrm{xxxvii}}$ explain that as a principle of production, modularity has had a long history. "Manufacturers have been using it for a century or more because it has always been easier to make complicated products by dividing the manufacturing process into modules or cells."

Understanding the concept of modularity is not limited to the realm of product design and organizational structure in economics and business management analysis. Schilling $(2003)^{\mathrm{xxxviii}}$ points out that there are numerous researchers in various academic fields of psychology, biology, mathematics, and even American studies which have utilized the concept of modularity in several instances.

Fodor $(1983)^{\mathrm{xxxix}}$ asserts that the mind is composed of modules. In addition to his notion of fundamental cognition, modular structures in visual processing (Marr, 1982) ${ }^{\mathrm{xl}}$, in much of

\footnotetext{
${ }^{1}$ Physical objects include information as resources such as customer credit information and market research.
} 
higher cognition and intellectual skills (Gardner, 1983) ${ }^{\mathrm{xli}}$, in language processing (Jackendoff, 1997) ${ }^{x \text { lii }}$, and in musical cognition (Lerdarl and Jackendoff, 1983) ${ }^{x \text { liii }}$ are among the areas which have been researched extensively in psychology and cognitive science.

In computer science, modularity is a property of computer programming in which separate units operate only through defined interfaces and then are reusable and flexible for changes. A module is also described as an "object" and the methodology to pursue modularity “object-oriented approach" (Garud and Kumaraswamy, 1996) ${ }^{\text {xliv }}$. These module-related concepts are widely accepted particularly in large-scale programming.

The definitions appearing on the literatures among the various academic domains above have a common theme, and the description of a unit as relatively tightly and coherently coupled/connected inside and at the same time relatively loosely and weakly outside is well accepted (Ulrich, 1995) ${ }^{\mathrm{xlv}}$, (Baldwin and Clark, 2000) ${ }^{\mathrm{xlvi}}$, (Schilling, 2000). As a result, substitution among modules and independency (autonomy) within a module are strengthened. These are other aspects that make modularity a popular research topic under the recent business environment where competition by independency and individuality becomes more fierce and important.

There are also a few empirical studies on topics including product design and manufacturing of automobiles (Ulrich, 1995) (MacDuffle, Sethuraman, and Fisher, 1996) xlvii $_{\text {(Robertson and }}$ Ulrich, 1998) ${ }^{\text {xlviii }}$ (Thonemann and Brandeau, 2000) ${ }^{x l i x}$ (Kamrani and Salhieh, 2002) ${ }^{1}$ computers (Langlois and Robertson, 1992) ${ }^{\mathrm{li}}$ (Feitzinger and Lee, 1997) ${ }^{\mathrm{lii}}$ (O'Grady, 1999) $)^{\text {liii }}$ (Baldwin and Clark, 2000) (Christensen, Raynor, and Verlinden, 2001) $)^{\text {liv }}$, home appliances (Langlois and Robertson, 1992) (Meyer and Lehnerd, 1997) ${ }^{\text {lv }}$ (Lee and Tang, 1997) ${ }^{\text {lvi }}$ (Loch, Terwiesch and Thomke, 2001) ${ }^{\text {lvii }}$ (Worren, Moore, and Cardona, 2002) $)^{\text {lviii }}$, bicycle (Randall and Ulrich, 2001) ${ }^{\text {lix }}$, etc.

Contradictions are apparent, however, in the fact that even integration models or integral architecture often labeled as the inverse structure of modularity; and non-substitutable components bundled into a single integrated package (Schilling, 2000) utilize modules. For instance, automobile manufacturers which are often perceived as integral modelers have been using numerous modular parts, such as standards specified by the Society of Automotive Engineers; common components and platforms in many different models, etc. (Sanchez and Mahoney, 1996) ${ }^{\mathrm{lx}}$. In general, as discussed in the previous chapter, it can be stated that almost all systems are recognized "to some extent", as modular (Schilling, 2000) but that the level of modularity has not been clearly designated. 
This research provides an overview of the terminology and concepts associated with the basic framework that defines a module as an autonomous entity, and economic transactions as the interactions among these modules operating in a substitutable and reusable mode (being "fungible", can be "transferred" "supplanted", and "redeployed without sacrifice of productive value" by what Williamson (1985) used to explain as "asset specificity", the most important dimension of transaction costs) through interfaces. In this regard, modularity is an important issue to analyze and verify transaction costs and also the dynamic mechanisms behind interfaces that exist within entities, organizations, networks, and the society that we live in today. 


\section{Definition of Terms}

In this chapter, we confirm the terms for further analysis and discussion.

\section{ENTITY}

Entity is a person or a group of person with capability and willingness to carry out autonomic economic decision making and to enter into transactions with other entities.

\section{TRANSACTION}

Transaction is the exchange of goods/services, through markets or within organizations, and ex ante and ex post related activities to complete the exchange.

\section{INTERFACE}

The terminology interface appeared first in the definition of transaction by Williamson (1985) as "the transfer of a good or service across a technologically separable interface." It also plays an important role from modularity perspective which Baldwin \& Clark (2000) defined it as the description of how the different modules will interact, fit, connect and communicate. In this research, following Williamson, interface is defined as the parameters/media through which transactions are made between two entities through markets or within organizations. Interface consists of elements at exchange, and in ex ante and ex post exchange (see figure 1).

\section{EX ANTE EXCHANGE}

-Connection: basic infrastructure of communication, such as, (a) access point: acquiring address and traveling; (b) synchronization of medium and tools: communication platform (natural language ${ }^{2}$, protocol, tool, signal, etc.), time, space, participants, etc.; (c) synchronization of logic (law, measuring system, custom, etc.).

-Information gathering: formatted information presentation and search/discovery of information about a trading party (authentication, credit guarantee) or about a good/service (specification/quality, compensation, customization, delivery, necessary resources).

-Mutual understanding and agreement: negotiation, coordination, agreement and contract about specification of good/service and other transaction conditions

\section{AT EXCHANGE}

-Exchange and Logistics, such as, (a) supplier to buyer: delivery of good/service (transportation and transfer of ownership); (b) buyer to supplier: supply of necessary resources; and (c) compensation.

\footnotetext{
${ }^{2}$ People spend huge amounts of investment for mastering this communication channel. Companies in nonEnglish speaking countries such as Japan need additional and greater investments on the establishment of the channel. These costs normally do not come up.
} 


\section{EX POST EXCHANGE}

-Inspection and Integration: monitoring/inspection, switching (integration, training/education including management), evaluation/improvement, problem solving and forcible execution.

Those elements are in sequential and complementary structure from the beginning through the end of transaction. Interface also consists of fixed interface and ad hoc interface. All decisions and actions in a transaction are ruled by fixed interface and/or ordered by ad hoc interface as below.

We came up to this framework through the inductive analysis of hundreds of real transactions, especially of the standards of information technology arena such as EDI, Rosettanet, ebXML: eBusiness eXtensible Markup Language, etc. which are or are based on the standardization initiatives of the United Nations. Many of the information technologies have been developed for the purpose of reducing transaction $\operatorname{costs}^{3}$ and those standardization initiatives try to cover all the kinds of transactions in the business world.

\section{Figure 1: Functions and Elements of Interfaces}

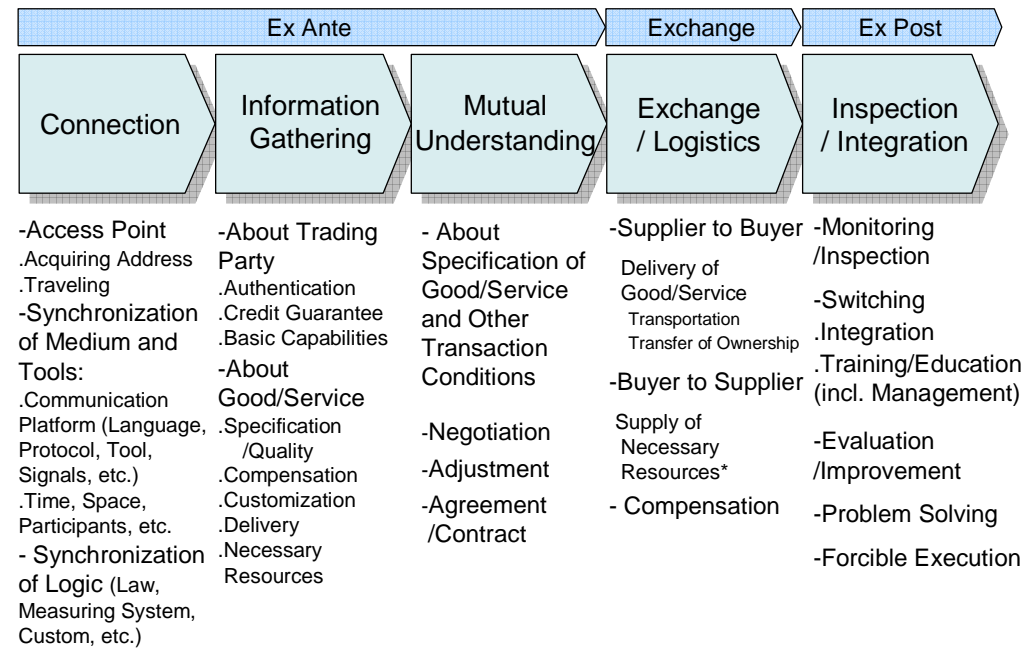

* Assets such as facilities, machines, systems, processes, etc., human resource, capital, brand resource to execute mission.

\section{FIXED INTERFACE (FIF)}

Fixed interface is priori agreed rule and/or medium through which transactions are made between two entities. FIF may be explicit or implicit. Explicit FIF includes physical and

\footnotetext{
${ }^{3}$ Information technologies deal with information of transaction and information as resources (production). The analysis of the former benefits for understanding transactions.
} 
social infrastructures including telecom system, hardware, durable equipment, electric signal, legal system, authentication system, credibility guarantee system, management system, etc. Implicit FIF includes reputation and ostracism and ingroup social communications networks as North $(1997)^{1 \times i}$ designated as well as custom, norm, trust, credibility, reputation, policy, strategy, philosophy, culture, threats, respect, etc. Those may be described explicitly and defined as explicit FIF. FIF becomes explicit when rules are expressed and defined clearly enough for a third person or an outsider to understand.

The notion of "political transaction costs" introduced by Furubotn \& Richter (1997) accords with the social infrastructures above. Taxes are considered to be the operation costs of social infrastructures. Monetary system is also an important FIF as lubricant to reduce friction (Mill, $1857)^{\text {lxii }}$.

Fixing interface means specifying parameters/media of interface and actions in transactions. Common combination patterns of elements, media and actions (structure, sequence, etc.) are extracted from all the transactions which FIF is planned to cover and which transaction entities have to comply with to facilitate the repetition of the pattern that reduces the total cost of transaction by stimulating economies of scale and scope. Any element of the interface could be fixed separately or jointly, by development or procurement.

We intentionally avoid using the terminology standard, instead of fixing, as it has ambiguous multiple meanings which we will discuss later.

\section{AD HOC INTERFACE (AHIF)}

Although there seems to be no interface when activities of two entities have to be closely and coherently coordinated, certain kinds of interface must exist for as long as those are interacting physically and/or functionally even if not defined or ruled. The difference is whether it is fixed or ad hoc. Coordination is important when a complex product does not have well defined interfaces between components (Collis and Montgomery, 1998) $)^{\text {liii }}$, and ad hoc interface is the result of coordination. Ad hoc interface is usually order for an action in a transaction for one time usage, which is not fully ruled, agreed, programmed nor planned in advance, while FIF is used at least twice (the frequency of use should compensate the costs accruing for fixing). Williamson (1985) designated the notion of AHIF as selective intervention for uncertainties which are not able to priori fix. Milgrom \& Roberts (1992) pointed out synchronization problems and assignment problems of design attributes and innovation attributes as examples of uncertainty. When a problem requires a different 
sequence of synchronized actions, when a problem requires the assignment of different employees with different capabilities, and when a problem requires a different information as the environment has innovated, coordination is important, that is, AHIF. In contract theory, ownership is composed of control rights, residual control rights, and residual claims and those are supposed to be defined, otherwise it would be impossible to complete contracts (Alchian and Demsetz, 1972) ${ }^{\text {lxiv }}$. Residual control right is "the right to determine how the asset is used in circumstances not covered by existing contracts, customs, or the law" (Baker and Hubbard, $2001)^{\mathrm{lxv}}$. In organizations, the commands which those with residual control rights give are AHIFs, and ownership and control rights are allocated by FIFs. The FIFs related with ownership replace many AHIFs in which "motivation costs" are incurred (Milgrom and Roberts, 1992) in connection with understanding, directing and monitoring the subordinate, or increasing his motivation and nominal efficiency. Menard (1996) describes this discretionary power as "[T]his capacity to command requires a formal status based on rights and rules defined at the level of the 'institutional environment': supervisory functions indicate the presence of organizations as specific 'governance structures' for processing transactions." While FIF fixes activities for more than once such as at the future expansions of functions or products, AHIF is more flexibly and freely redesigned before the widely applicable FIF is known. Options are specified by FIF and the selection of options/modules is AHIF while the criteria of selection are FIF. AHIFs are for uncertain events which are not priori specified such as transaction problems not covered or described in a contract, including:

-Vertical AHIF: decision of the control right wielder who is designated by contract including "fiat" as selective intervention from superior on formal authority in organization (Menard, 1996) ${ }^{1 x v i}$

-Horizontal AHIF: order emanating from wielders of authority in formal/informal arbitration or coordination agreed by the transaction entities

Furubotn \& Tichter (1997) ${ }^{\text {lxviii }}$ introduced the notion of fixed and variable transaction costs, the specific investments made in setting up institutional arrangements and costs that depend on the number or volume of transactions, respectively. Those are consistent with fixed interface related costs and ad hoc interface related cost in this research.

\section{TRANSACTION COST}

Transaction cost has been recognized as friction of exchange. It is incurred at interfaces which should exist between transaction entities. Transaction costs include costs related to interfaces, such as initial development costs for designing and infrastructure/media, operation costs for administrative works and infrastructure/media, switching costs such as training/education, 
integration and other managerial activities including enforcement.

Therefore, in this research, transaction costs are defined as the costs of resources utilized for the creation, maintenance, use, and change of interfaces in institutions and organizations, following Coase (1960) ${ }^{4}$.

We can also divide the transaction costs into two categories: AHIF related costs and FIF-related costs (see figure 2). As FIF is used for multiple transactions, development cost, switching cost, and operation cost of FIF should be allocated to each transaction.

Figure 2: Definition of Fixed Interface and Ad Hoc Interface

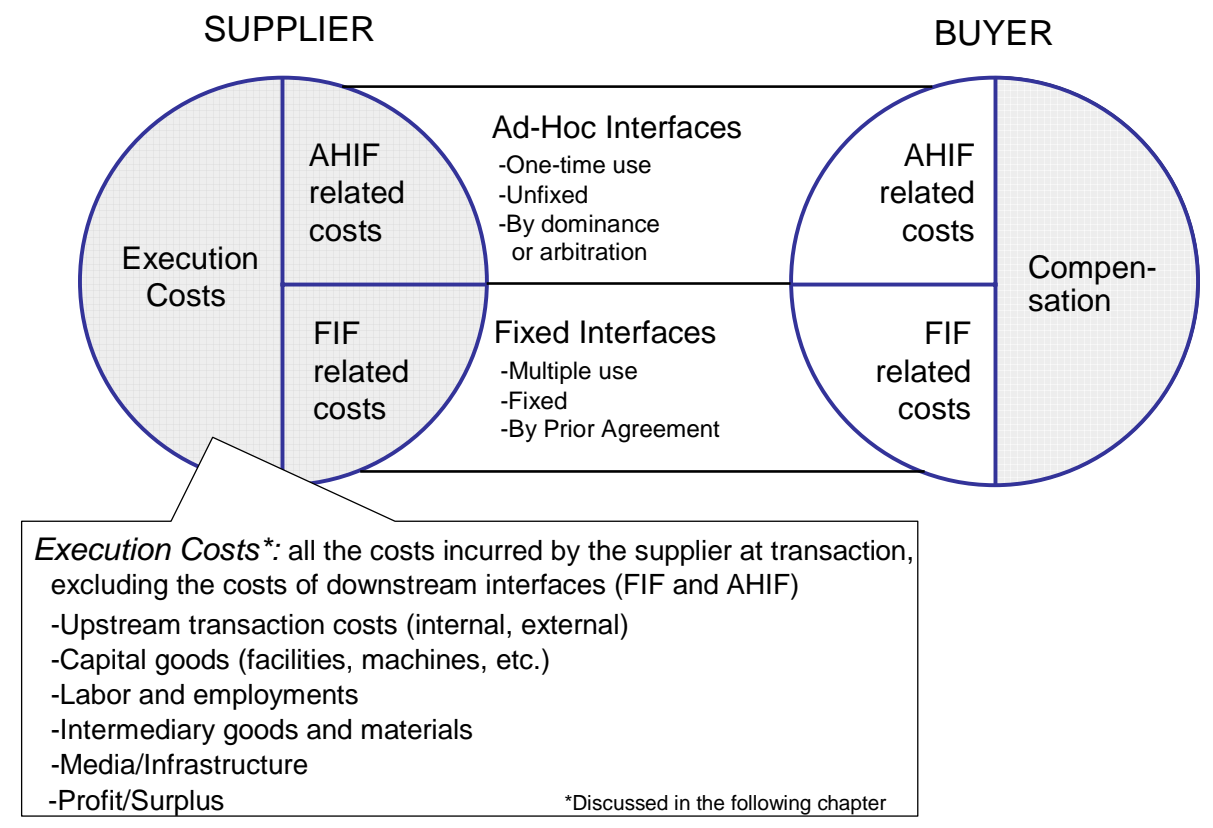

Through one transaction, only one unit of good or service is exchanged with compensation which contains the price of the good or service and/or other types of remuneration, the buyer spending his own transaction costs to procure the good or service. The transaction cost of the supplier may or may not be directly inclusive of his price.

\section{COMPENSATION}

Good/service is obtained at cost of compensation and the demander's activities related with FIF and AHIF.

\footnotetext{
${ }^{4}$ Coase's definition is "the costs of resources utilized for the creation, maintenance, use, and change of institutions and organizations." (Coase, 1960)
} 


\section{TRANSACTION CHAIN}

To produce Good/Service A which is exchanged in a transaction, Good /Service B1, B2, etc. are procured. To produce Good/Service B, Good/Service C1, C2, etc. are procured. These go on and form the chain (figure 3 ).

\section{Figure 3: Transaction Chain: Mandala}

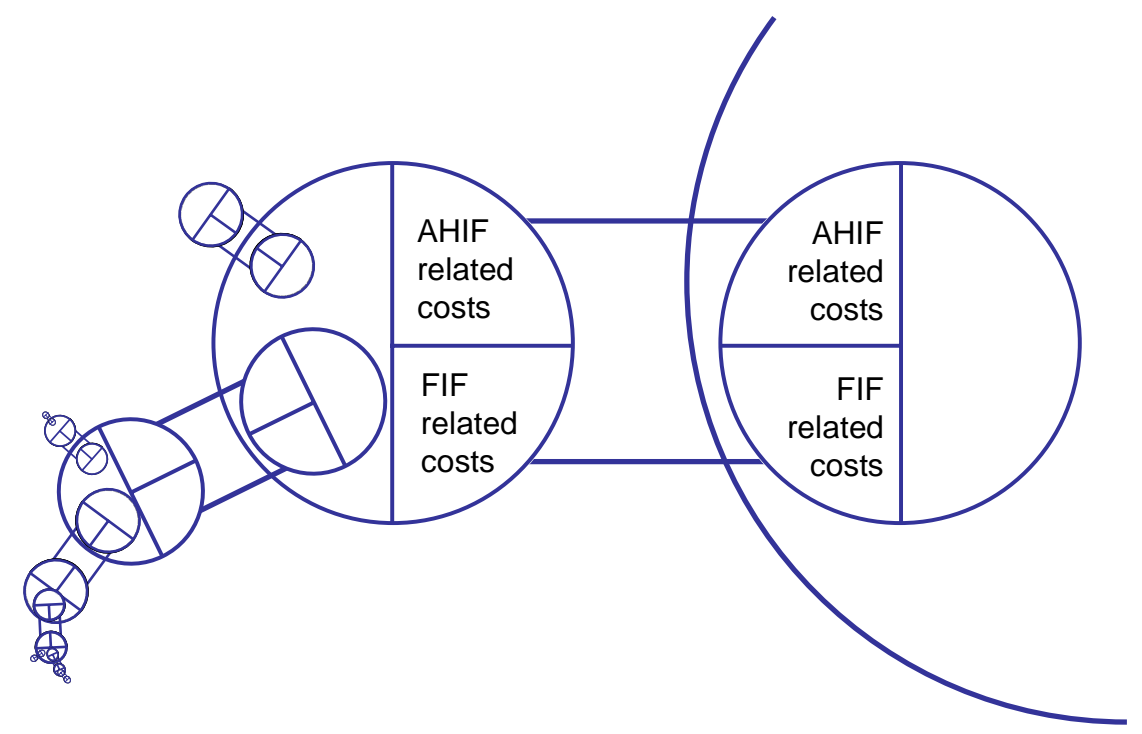

\section{ARCHITECTURE}

Transaction is ruled by a collection of interfaces which are layered and sequential. Architecture is designed structure of a nexus of FIFs defining the interaction of interfaces. The design consistency of the architecture should avoid the excess transaction costs such as the unnecessary deployment of AHIFs.

\section{OPEN / CLOSED FIF}

FIF may be open or closed in terms of the right of use such as the price. Closed FIF requires exclusive conditions for use and/or payment of some user fees. FIF is classified as follows:

1) Open (non-exclusive) or closed right of use

2) Means to finance development and operation costs

- charged to users (user fees and membership fees)

- allocated to developer (developer fees)

- not charged or allocated but recouped from other external sources such as sponsor or advertisers targeting the users of FIF

Open FIF is more open in terms of the right of use such as free of charge for users. 


\section{MODULE}

A module is a component, a product part, software, or an entity substitutable with another without sacrifice of productive value ${ }^{5}$. It is independent (autonomous if it is an entity) and interactive under regulation of interfaces commonly shared with potential substitutes. In order to be shared, the interfaces should be explicit FIFs, not implicit FIFs nor AHIFs.

Entities are said to be more modular, the more shared interfaces they depend upon, to be precise, those interfaces that are not AHIFs but the more widely accepted FIFs (such as Open FIFs, not implicit FIFs).

A module does not need to be internally coherent as definitions commonly designate. A module may consist of modules in its internal structure as long as it is substitutable externally. This is further discussed in the context of the level of modularity in the Chapter 6 of this paper.

\footnotetext{
${ }^{5}$ Williamson (1985) explains asset specificity as a characteristic of an "asset [which] cannot be redeployed without sacrifice of productive value."
} 


\section{Model}

In this chapter, we present our terminologies and conceptual model.

\section{COSTS}

-Execution Cost of Interface:

Execution cost is the cost for an entity to execute activities ruled by interfaces, such as production of goods/services and resources, and FIF development ${ }^{6}$. The concept of execution costs cover all the costs incurred by the supplier at transaction, excluding the costs of downstream interface (FIF and AHIF) related costs. Execution costs include the costs of upstream interface related costs, purchase of goods/services such as capital goods (facilities, durable equipment), labor and employment, media, infrastructure, intermediate goods and materials, upstream transaction costs (upstream interface related costs), and profit or surplus for transaction (see figure 2). The sum of production and transaction costs, rather than production costs alone, should be economized by economic agents (Aggarwal and Walden, $2005)^{\text {lxix }}$ but transaction costs in production cost have not been clearly defined. So we distinguish execution cost from production cost, explicitly separating transaction costs in production costs.

-Development Cost of Interface:

Development cost is incurred in designing and developing interfaces. This includes the purchase of durable equipment and the acquisition of media and infrastructure (particularly for FIF). This corresponds to the costs incurred at the all interface elements of interface (FIF and AHIF) development transactions; namely, connection, information gathering, mutual understanding, execution costs, exchange/logistics, and inspection/integration (see figure 1), excluding those costs below.

-Operation Cost of Interface:

Operation cost is the regularly accruing costs for operating and maintaining FIF. It includes renegotiation, monitoring, evaluation, and revision. This cost is included in the execution costs of FIF development transaction.

-Switching Cost of Interfaces:

Switching cost is the cost for an entity to understand, switch, and adjust its activities, and to

\footnotetext{
${ }^{6}$ Because FIF related costs are included in transaction costs, the execution costs of FIF development are included in transaction costs in the broad definition of the term.
} 
make the other entity understand, switch, and adjust, to newly deployed interfaces. Switching costs include costs incurred in the conduct of activities to obtain commitment such as those related to informing, education and management, etc. This cost corresponds to the costs incurred at the interface of switching.

\section{MODELING}

We describe a proposed framework of interface in this research keeping in mind its possible applications to various fields. The basic model shown in figure 4 delineates the essential relationships that comprise the transaction.

\section{Figure 4: Basic Model}

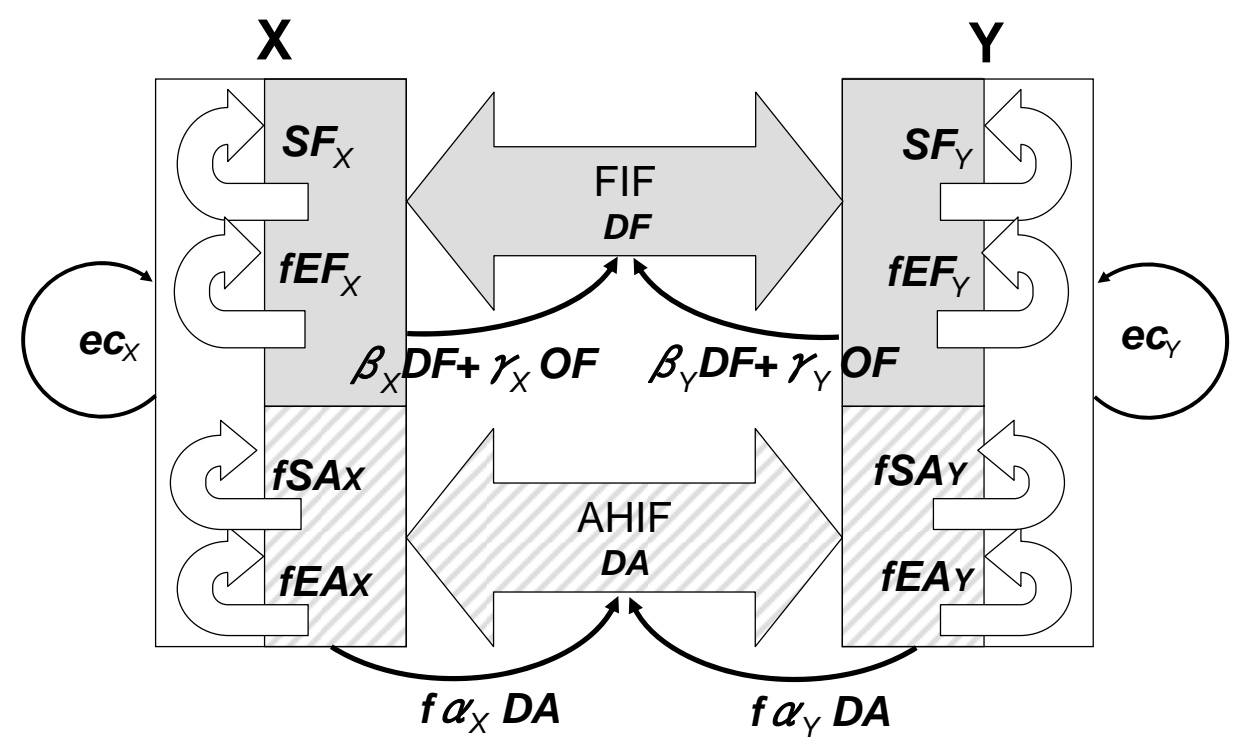

There are supposed to be two entities, named $\mathrm{X}$ and $\mathrm{Y}$, engaged in a transaction whereupon the corresponding transaction costs and execution costs ( $e c_{i}, i=\mathrm{X}$ or Y. $e c_{y}$ is compensation) are incurred. Initially, they only use AHIFs which are developed at each transaction and share the development cost of AHIF $(D A)$ in a certain way $\left(\alpha_{x}+\alpha_{y}=1\right)$. So they pay $f \alpha_{i} D A(i=\mathrm{X}$ or $\mathrm{Y})$ to develop AHIF. In addition, they pay switching costs ( $f S A_{i}, f$ is a frequency of transactions) and execution costs $\left(f E A_{i}\right)$. Entities recognize the efficiency of deploying FIF upon the continued use of AHIFs. To use FIF, development cost $(D F)$ and operating cost $(O F)$ of FIF are incurred. Here, we assume that entities $\mathrm{X}$ and $\mathrm{Y}$ share these costs and pay $\beta_{i} D F+\gamma_{i} O F$ $\left(i=\mathrm{X}\right.$ or $\mathrm{Y}$ ) to develop and maintain FIF. In addition, they need to pay switching costs $\left(S F_{i}\right)$ to adopt their operation to FIF. So the total transaction cost (TTC) incurred by an entity $i$ ( $i=\mathrm{X}$ or $\mathrm{Y})$ with certain frequencies $f\left(1 \leq \mathrm{f} \leq \mathrm{S}_{\mathrm{F}}, \mathrm{O}_{\mathrm{F}}, \mathrm{E}_{\mathrm{F}}, \mathrm{D}_{\mathrm{A}}, \mathrm{S}_{\mathrm{A}}, \mathrm{E}_{\mathrm{A}}\right)$, where $\mathrm{S}_{\mathrm{F}}, \mathrm{O}_{\mathrm{F}}, \mathrm{E}_{\mathrm{F}}$ are frequencies of 
switching, operation, and execution of FIF and $\mathrm{D}_{\mathrm{A}}, \mathrm{S}_{\mathrm{A}}, \mathrm{E}_{\mathrm{A}}$ are frequencies of development, switching, and execution of AHIF, respectively, is shown as follows:

$$
T T C_{i}=\left(\beta_{i} D F+\sum_{f=1}^{S F} S F_{i f}+\sum_{f=1}^{O_{F}} \gamma_{i} O F_{f}+\sum_{f=1}^{E F} E F_{i f}\right)+\left(\sum_{f=1}^{D A} \alpha_{i f} D A_{f}+\sum_{f=1}^{S_{A}} S A_{i f}+\sum_{f=1}^{E A} E A_{i f}\right)
$$




\section{Discussion}

\section{MULTI-LAYERED STRUCTURE of INTERFACES}

Interfaces are built up on existing interfaces and constitute multilayer (see figure 5). Customs such as natural language, measuring system and semantics exist as basic FIF without any specification from entities, and the company establishes organization governance and concludes contracts on those FIFs. Their internal accounting rules and management systems are constructed on them and so on. This layered structure requires companies to expand their size in order to finance the costs related to FIF, especially in the meta-level.

Although the transactions become more efficient with the deployment of FIF and consequently the changes on and above the FIF come to be less costly (if designed so and committed), the replacement of FIF always proves to be more difficult as the switching cost of FIF is larger than that of AHIF. Especially so does the replacement of meta level FIF because it requires many other FIFs to change on the FIF. This means the design of FIFs are crucial for the adaptability of entities.

Figure 5: Layers of Interfaces

\begin{tabular}{|c|c|c|c|c|c|c|}
\hline 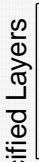 & $\begin{array}{c}\text { Continuous } \\
\text { Ordering }\end{array}$ & $\begin{array}{l}\text { Add newly } \\
\text { developed } \\
\text { ordering } \\
\text { interfaces }\end{array}$ & $\begin{array}{l}\text { Understand } \\
\text { present } \\
\text { statuses }\end{array}$ & $\begin{array}{l}\text { Negotiate about } \\
\text { conditions of } \\
\text { delivery, } \\
\text { price, quality, } \\
\text { etc. }\end{array}$ & $\begin{array}{l}\text { Order } \\
\text { /procure } \\
\text { /pay } \\
\text { /transport }\end{array}$ & $\begin{array}{l}\text { Integrate } \\
\text { /Inspect }\end{array}$ \\
\hline $\begin{array}{l}0 \\
\text { जी } \\
0 \\
\frac{0}{0} \\
\sum_{0}^{0}\end{array}$ & $\begin{array}{c}\text { New } \\
\text { Transactions } \\
\text { Development }\end{array}$ & $\begin{array}{l}\text { Add newly } \\
\text { developed } \\
\text { relationship } \\
\text { interfaces }\end{array}$ & $\begin{array}{l}\text { Understand } \\
\text { schemes } \\
\text { (good,/service, } \\
\text { responsibility } \\
\text { /authority) }\end{array}$ & $\begin{array}{c}\text { Contract after } \\
\text { adjustment } \\
\text { and agreement } \\
\text { (transactions) }\end{array}$ & $\begin{array}{l}\text { Develop } \\
\text { relationship } \\
\text { specific } \\
\text { interfaces }\end{array}$ & $\begin{array}{l}\text { Monitor } \\
\text { /Evaluate } \\
\text { /Enforce }\end{array}$ \\
\hline$\frac{\overline{0}}{\frac{0}{0}}$ & $\begin{array}{c}\text { Basic } \\
\text { Relationships } \\
\text { Development }\end{array}$ & $\begin{array}{c}\text { Select social } \\
\text { common } \\
\text { platforms }\end{array}$ & $\begin{array}{l}\text { Understand } \\
\text { entities } \\
\text { (company, } \\
\text { individual, etc.) }\end{array}$ & $\begin{array}{l}\text { Contracts after } \\
\text { adjustment } \\
\text { and agreement } \\
\text { (relationship) }\end{array}$ & $\begin{array}{l}\text { Develop user } \\
\text { specific } \\
\text { platforms }\end{array}$ & $\begin{array}{l}\text { Evaluate } \\
\text { /Improve } \\
\text { relationship }\end{array}$ \\
\hline & & Connection & $\begin{array}{l}\text { Information } \\
\text { Gathering }\end{array}$ & $\begin{array}{c}\text { Mutual } \\
\text { Understanding }\end{array}$ & $\begin{array}{l}\text { Exchange } \\
\text { / Logistics }\end{array}$ & $\begin{array}{l}\text { Inspection } \\
\text { / Integration }\end{array}$ \\
\hline & & & & & \multicolumn{2}{|c|}{ Sequence of Transaction } \\
\hline
\end{tabular}

\section{FUNCTIONS of FIF}

The essential function of FIF is the reduction of transaction costs by fixing so that entities can reduce the cost per transaction (division) or increase the number of transactions keeping the cost constant (interconnection). 
1) DIVISION (decomposition, separation, disintegration):

FIF decreases unnecessary transactions of AHIFs, divides a unit (a resource without any FIF inside) into two sub-units increasing their independence due to the extraction of common elements. AHIFs which can be replaced by FIFs include any kind of transaction elements. Even the specifications-related interfaces of a product can be divided into various elements of interfaces such as physical (mechanical) elements, input/output (medium, protocol, processing logic, etc.), and power (these also correspond to transaction elements). The decrease of interfaces between the two sub-units makes the unit appear "divided." Researchers have recognized system as more modular when their components can be disaggregated and recombined into new configuration with little loss of functionality (Langlois, 1992) (xxvii $^{\text {lxw }}$ (Sanchez, 1995) ) $^{\text {lxviii }}$ (Schilling, 2000). Therefore, the division makes the sub-units modular.

There are two types of division (decrease of interfaces by deployment of FIF) of a unit: vertical division and horizontal division.

-Vertical division: Vertical division exists between a superior and a subordinate in organization or market for purposes of (i) transferring ownership (delegating control rights

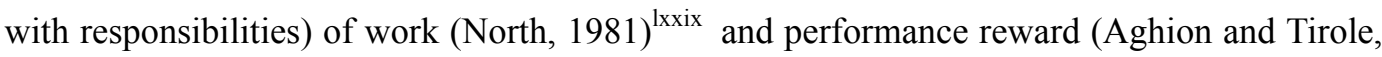
1997) ${ }^{\mathrm{Ixxx}}$ (Baker, Gibbons and Murphy, 1999) ${ }^{\mathrm{lxxx}}$, (ii) reducing the risk of moral hazard upon evaluation by the superior (Milgrom and Roberts, 1992), (iii) decreasing the superior's selective interventions and monitoring, and (iv) ensuring independence (autonomy) of the subordinate, all of which provide incentives for him/her to commit to the contract. Both entities also can concentrate on their managerial and operational specialties (Cheung, 1998) to achieve higher efficiency utilizing independence (autonomy), simplicity and economies of scale.

-Horizontal division: A unit is divided into two sub-units according to their similarity (based on functions, specialties, etc.) for the purposes of ensuring independence and achieving higher efficiency. The most frequent occurrences in the transactions between the buyer and the sub-units which are mutual understanding, knowing work specifications and surplus capacities at the moment, ordering/invoicing, monitoring, evaluation, etc. are fixed and the total number of interfaces is decreased. For instance, when a company is "divided" into sales and manufacturing departments, the most frequent transaction elements between the president (the proxy of their buyer) and departments which are the basic assignment of tasks to discrete department are fixed. The consequent specialization increases their efficiency of performance as Smith (1776) $)^{\text {lxxiv }}$ noted first. 
Hereby, as one virtual interface appears to divide a unit into two, let us call this set of interfaces "quasi-interface".

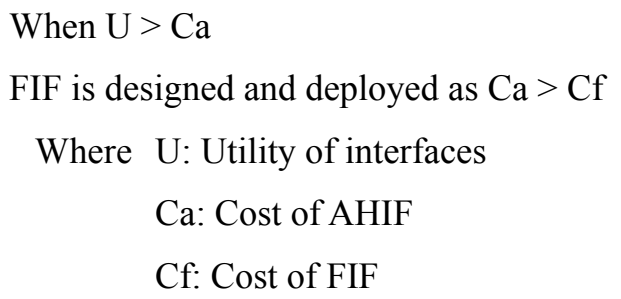

2) INTERCONNECTION (connection, integration, mixing, combination):

Interconnection is the existence of one or any of elements of interfaces between units. FIF establishes necessary transactions for units which are even deemed too costly to exist between units either they are divided from one unit or originally independent.

$$
\text { When } \mathrm{U}<\mathrm{Ca}
$$

FIF is designed and deployed as $\mathrm{U}>\mathrm{Cf}$

For instance, the Internet has established various FIFs and enabled costless transactions for two entities at both sides of the globe. A new president of a company may set up FIF of regular meeting for adjusting sales activities of two business unit managers between whom would prove too costly to communicate due to the historical emotional conflicts between them.

Assuming the output of entities is constant and entities always pursue the best utilization of resources with the use of AHIF or $\mathrm{FIF}^{7}$, the decrease of transaction costs resulting from the deployment of FIFs is equal to the increase of utilities. Addition of value equals the reduction of transaction cost (Anderson, 1995) ${ }^{\text {lxxxv }}$ (Cannon and Homburg, 2001). ${ }^{1 \times x x v i}$ Inasmuch as the reduction of transaction costs results in the increase of the number of transaction, the execution cost at each transaction or the possibility of accessing entities with more valuable resources also increase the volume of value. Therefore, this research focuses on cost reduction, not benefit nor value added.

As the divisions (decomposition) and the interconnections of resources within organizations and in markets advance, the complex of interfaces constitutes corporate or inter-corporate structure. The basic benefits of division and interconnection can be also explained as shown in figure 6 while the dynamic aspects of the development of division and interconnection in organization are also described later as "the staged growth of company."

\footnotetext{
${ }^{7}$ Opportunity costs of not acknowledging the most efficient resources are negligible in the era of the Internet. If resources are not selected, they are simply due to the larger transaction costs. That is, opportunity cost itself could be negligible.
} 
Figure 6: Benefits of Interfaces: Efficient Utilization of Resources

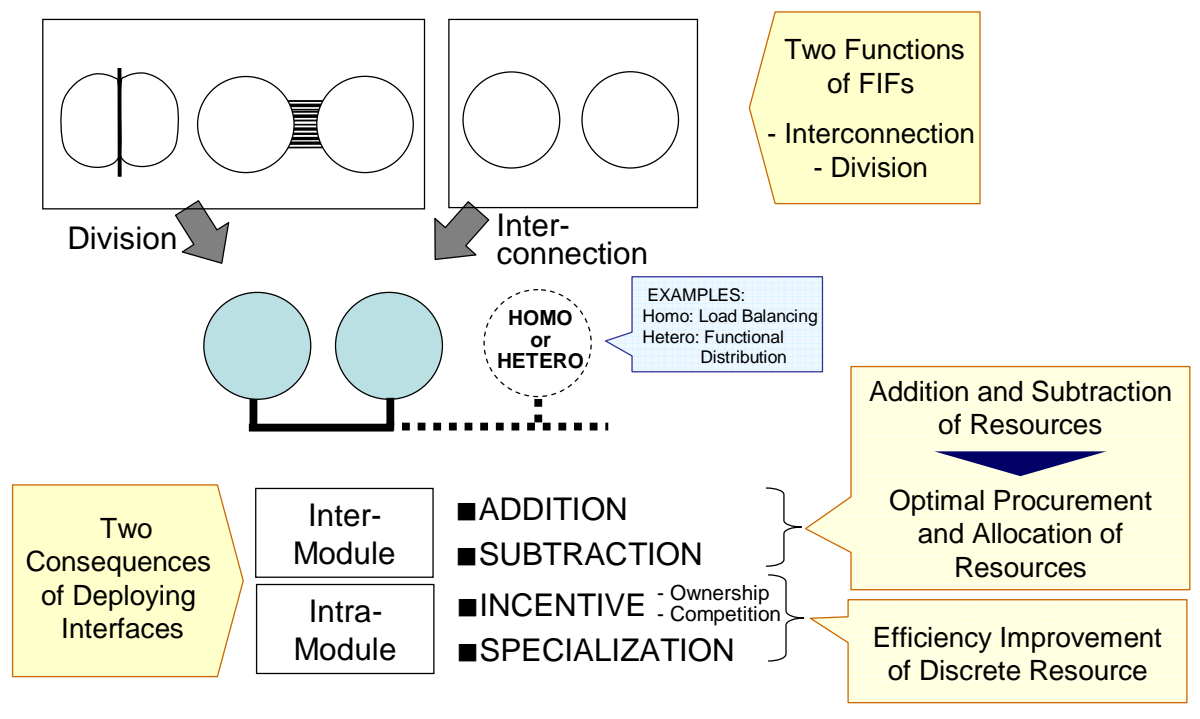

Figure 6 exhibits that FIFs enable efficient utilization of resources both among modules and inside module through division and interconnection.

As inter-module structure, the addition and the subtraction of resources are managed on a module basis where interfaces (FIF) are established and shared among the modules. Homogeneous and heterogeneous modules are procured and allocated, so that the load balancing and functional distribution are achieved respectively. It proceeds toward the optimal point.

Baldwin \& Clark (2000) pointed out six values of modularity: splitting, substitution, excluding, augmenting, inversion and porting. Those can be explained by the combination of the functions of FIF: division and interconnection, and the dynamic consequences of FIF deployment: addition and subtraction. Splitting is an equivalent of division. Substitution is a combination of subtraction and addition. Exclusion is subtraction and augmenting is addition. Inversion is a combination of subtraction and conjunction (integration). Conjunction and integration are other expressions of interconnection with emphasis on a comprehensive connection of entities. Porting is an independent topic related to the open compatibility of FIF discussed later. Again, FIFs reduce the transaction costs such as mutual understanding, knowing work specifications and surplus capacities at the moment, ordering/invoicing, evaluation, and reassignment by replacing AHIFs and achieving the more optimal 
management of resources. Resources mean labor, capital, material, equipment, management, etc. Resources with specificity or with occasional transaction are more costly to deploy FIFs on account of their less frequent transactions and the greater difficulty of controlling the efficiency of utilization.

As intra-module structure, the ownership decreases the motivation costs or strengthens the incentive to increase one's own personal rewards. The competition as a result of the interconnection and the reduction of transaction costs between the buyer and the substitutes goes a long way to decreasing the costs that are the own negative personal rewards (substitution by competitors). Discrete modules are willing to increase their efficiency as they are incentivized to commit their contracts in addition to the effect of economy of scale by specialization (caused by the increased frequency of transaction patterns).

While the diversity of resources advances resulting from the increases of ownership, competitive differentiation strategy, and efficiency by specialization, the liquidity (the substitutability) of resources advances attributable to the increased interconnection. The resources are managed in a better way when FIFs are well deployed. Optimal procurement of external resources (hetero and homo) makes organization with the module and interface structure adaptive as a consequence.

Economy of scale in specialization among modules is mainly achieved through the reduction of the transaction costs per unit of such intangibles as mutual understanding of present conditions, negotiation, ordering, etc. attributable to handling a greater volume with a single transaction. One example is production process adjustments that Scherer \& Ross $(1990)^{1 \times x x v i i}$ observed as product-specific economies ${ }^{8}$. Economy of scale (EOS) also appears to occur with production costs but it actually does with transaction costs because production cost includes transaction costs internally. The EOS even in the case of pipe with larger diameter comes from the reduction of internal transaction costs, such as in development, designing, manufacturing preparation, etc. (in addition to the achievement of the larger capacity with the less material). This is applied to any kind of capital goods and labors. Learning curve experience effect also arises when FIF is able to be deployed with the accumulation of experiences. This could be applied to both institutions and individuals.

\footnotetext{
${ }^{8}$ Smith (1776) and Scherer \& Ross (1990) dealt with labor only while this paper includes general resources. Since interface is defined as for human activities, however, the interfaces of resources equal those of labor and management.
} 


\section{APPLICABLE AREA of FIF}

As figure 7 shows, some patterns in elements (or media and actions, structure, sequence, etc.) of transactions occur with a high frequency. During the planned period of FIF usage for all the related transactors, if the frequency of occurrence of specific pattern is high, it is more cost effective to deploy a FIF assuming that the initial and operation costs are constant.

If it is possible, however, to treat Patterns $\mathrm{C}$ and $\mathrm{E}$ together, they will be combined and selected to be extracted before Pattern A as "the possibility of aggregating the demands of similar but independent transaction is suggested" by Williamson (1985). For instance, they could be similar in terms of function, management level (upper, lower management and operation), business/product, region, client segment, and so on. The combination of similar patterns is an important managerial issue to address in proper application of FIFs to achieve maximum efficiency.

\section{Figure 7: Applicable area of FIF}

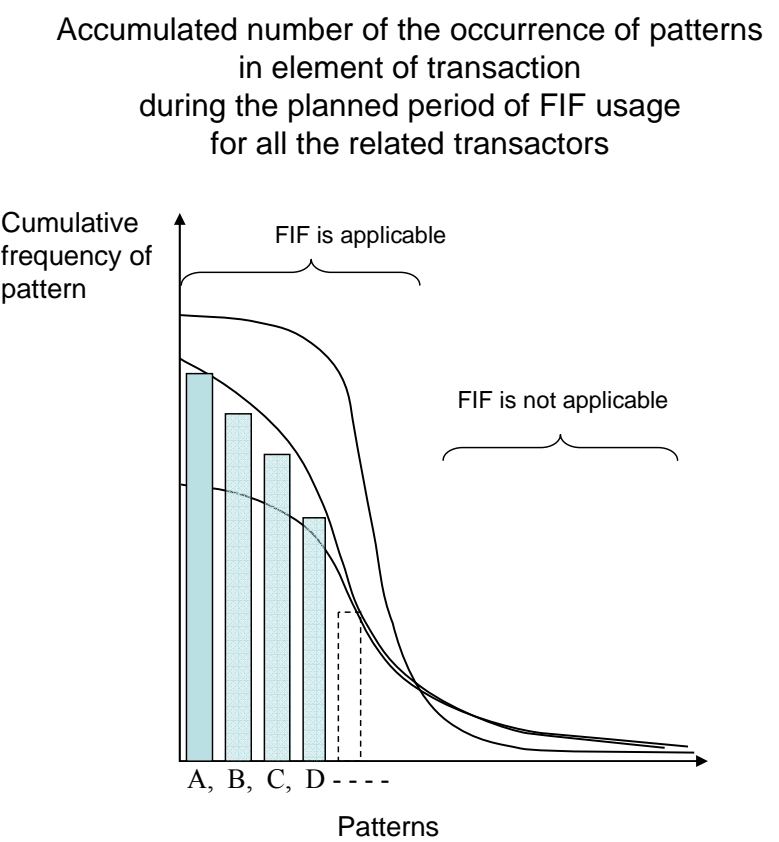

When the high frequency is analyzed, other types of network externalities should be considered. Through interface, user A can share the resources such as information with user B and user A (himself) in the future as well. For instance, a personal filing system works as FIF which rules information input and output activities of him/her at present and in the future and 
he/she is able to lower the transaction cost of transferring the information from the present to the future. Katz \& Shapiro $(1985)^{\mathrm{xcvi}}(1986)^{\mathrm{xcvii}}$ defined this as vertical network externalities.

\section{DEPLOYMENT of FIF}

As previously discussed, FIF is deployed between entities where AHIFs already exist (for the replacement of those AHIFs) or where transaction (AHIF) is too costly to exist. The FIF should be designed to satisfy the following objectives:

1) The newly deployed FIF should replace AHIFs as much as possible:

One FIF replaces as many AHIFs so that it finances the costs for deployment of FIF and reduces the costs of AHIFs as long as the benefits do not decrease. This is achieved by (1) designing FIF properly to function as a large number of AHIFs and to cover a large number of users in various areas, and (2) making those users commit to switch to the FIF.

2) FIF should consist of a minimum necessary amount of elements:

No unnecessary elements, media and actions should be included in FIF at the expense of benefits as these increase development, operation and switching costs.

3) FIF should be utilized to the maximum:

Fixing interfaces causes the repetition of the pattern of transactional activities and it should be utilized fully to reduce the total costs of transaction on account of economies of scale and learning experience effect. The management of FIF-related activities is important to reduce the costs.

4) FIF should be designed to keep development, execution and switching costs to the minimum:

If those costs related to the deployment of FIF are large, the reduction of transaction costs decreases. FIF should be designed to minimize the development and execution costs and the total switching costs of all the entities accumulated over a planned time period of FIF usage.

5) Conflicts with other FIFs should be minimized:

FIF should be designed to produce minimum conflicts or interferences with other existing FIFs or upcoming FIFs. Those conflicts should be solved by AHIFs to minimize the negative effects of contradiction which consequently incur additional costs.

The deployment of FIF is economically rational for transaction entities when their allocated development and execution costs as well as their switching costs related to FIF are lower than the allocated development costs related to all the AHIFs accumulated over a planned time period of FIF usage. 


\section{BENEFITS to OPEN FIF}

Benefit to open FIF, namely, to permit users to use non-exclusively and/or to make it free of charge, is to facilitate the dissemination of FIF and to strengthen its compatibility, which gives more opportunities of valuable transaction to the entities, and likewise benefits the FIF owner.

Users and owners derive different benefits from open FIF. The benefits to users are clearer. Because the specification of interface is open and the compatibility is secured, users can avert the lock-in to the owner of interface and urge the competition between owners (although they have more risks to be replaced by their equivalents or competitors). On the contrary, owners prefer keeping it closed to hold their asset specificity (specialty) and have users dependent on them. Competition increases the fungibility of owners. It is favorable for an owner who intends to start a relationship with a user while it is not for an owner to whom the buyer has been locked in.

Owners are required to satisfy the users' preference in the long term even though it is against their short term benefits. Competitive users or owners who are interested in utilization of external resources are more receptive to the idea of openness. Open FIF will acquire more competitive users, especially when it becomes the standard, and provide more access to external resources.

Opening FIFs is indispensable in particular when there is an existing defacto standard and someone introduces a new FIF to overcome it. Because users need switching costs to his new FIF, the price should be much lower than the existing one, sometimes free except variable costs like Open Source Initiative which competes with Microsoft with dominating FIF.

In traditional organizations, interfaces are more likely to avoid being fixed and open because transaction entities often prefer to keep FIF closed from the threat that he or she may be replaced by his or her equivalent. Employees, especially those with specific capabilities such as managers are afraid of loosing their specificity by exposure through FIF and prefer to keep FIF closed and maintain the differentiation of FIF and the value of investment. So do FIF owners who try to keep FIFs closed. As long as the most frequent pattern of AHIF transactions which originally do not make any differentiation, however, is appropriately fixed as FIF, it is expedient to open FIF, harmful to neither employees nor owners. The expectation or preference toward the opportunities for new transactions determines the differences above. Through opening the FIF, the possible utilization of external resources is added as one of its benefits which may result not only in considerable cost reductions, but may also open up 
channels to a wealth of resources.

\section{TRANSACTION in HIERARCHICAL ORGANIZATION}

The importance of transaction costs within formal organizations has been emphasized by both Coase $(1937)^{\mathrm{xcix}}(1988)^{\mathrm{c}}(1992)^{\mathrm{ci}}$ and Williamson $(1975)^{\mathrm{cii}}(1985)(1996)^{\mathrm{ciii}}$ and explored by researchers such as Groenewegen (1986) but still "few studies have been developed in this direction" (Menard, 1996). By our definition, transactions in formal organizations are ruled by FIFs such as rules, standards, norms, policies, custom, culture, trust and reputation existing in organization, and by AHIFs as a form of fiat and order from superiors on formal authority or wielders of authority in formal/informal arbitration. That is to say, an organization consists of FIF and AHIFs backed up by hierarchical authority which is also FIF. Hierarchy consists of managerial and functional authorities accorded with the ownership of control rights. FIFs (written responsibility and authority) to deploy or change FIFs are also determined. Thus, an organization can be understood as a nexus of FIFs of which "a nexus of contracts" (Alchian and Demsetz, 1972) occupies a large portion but not everything. This does not differ from any FIFs which organizes market exchange as Menard (1996) recognized. Employees' outcomes satisfying the specification from orders or rules are exchanged with reward and positive evaluation which may give rise to a bonus as well as promotion and higher salary in the future. Some examples of FIFs in organizations are explained below.

-Interface standards at company:

A collection of standards in an organization such as management rules, business processes, management systems, etc. functions as interface among employees through which the transactional activities in an organization are executed. Job descriptions enable manager and workers to communicate with each other to produce outcomes as priori agreed. Accounting and personnel rules have various interface functions for all employees and company.

-Quality standards at company:

Quality standards for specification and production process of goods/services are distinguished from interface standards in the research of standards (Grindley, 1995) ${ }^{\text {civ }}$ (David and Greenstein, 1995) ${ }^{\mathrm{cv}}$. As consumers, however, purchase and use of goods/services based on such qualities as specification of physical and performable configuration, those function as interfaces as well.

-Design philosophy:

In the designing process of interfaces of parts, design philosophy functions as a meta-interface 
to connect activities of the designers even beyond companies. Clark \& Fujimoto (1990) designated it as "product integrity" showing the automobile as an example of a product with integrity which the common philosophy had underlined as the quality and attribute that could spell the difference between a failed and successful product development.

-Trust:

Trust is mutually agreed meta-rule like code of conduct or custom. It enables handling uncertainties by coordinating different short-term interests among entities, and consequently it substitutes institutional arrangements $\left(\right.$ Levi, 2000) ${ }^{\text {cvi }}$. It will reduce the costs of credit guarantee and monitoring, etc. Opportunistic betrayals will collapse the interfaces not only with the specific transactor but also with the potential transactors and thereby raise the expected transaction costs considerably. As one-sided exploitation or concession (such as a boss exploiting his henchmen) does not maintain the long term trust-based relationship, skills on both sides to solve problems fairly are required. Furthermore, concepts, frameworks, technologies and terminologies of problem solving, which consist of complicated multi-layered interfaces, should be shared in advance. It is not a single or simple interface. Trust may be explicit with social infrastructure such as reputation database, credibility guarantee system, etc.

\section{TRANSACTION through MARKET}

Transaction through market is ruled by FIFs such as law, Law Merchant, custom, trust and reputation existing in market and explicit agreements such as contracts and AHIFs such as orders emanating from wielders of authority in formal/informal arbitration or coordination agreed upon by the transaction entities. Organization exists to reduce the transaction cost, but market as institution does the same purpose. It appears clearer with an artificial market on the Internet: eMarketplace. The artificial marketplaces on the Internet (both Business to Business and Business to Consumers) provide various contract-based interfaces between suppliers and buyers of goods/services usually commercially. FIFs such as authentication, credit guarantee, information provision in electronic catalog, negotiation platform, price formation (auction, reverse auction, etc.), logistics services, insurance, various types of consulting/integration services are provided and the transaction costs are drastically reduced. Many eMarketplaces have been competing with each other, targeting the same segments of the market, a kind of competition that often result in only a few survivals, the surviving FIFs becoming de-facto standards of the markets.

-Contracts in markets: 
Contracts are explicitly written FIFs for transactions through market. Problems derived from uncertain events should be solved by AHIFs under control rights described by all those FIFs which include the designation of arbitrators and legal systems, and so on.

-Qualification:

A person or a company qualified by a certain license can transact his/her asset easily in the market where the qualification is effective. For instance, ISO9000 qualification functions as the interface between qualified company and its potential clients. 


\section{Possible applications of the concept}

In order to explain the model and concept, some possible applications of the concept are presented in this chapter.

\section{PURPOSE of COMPANY}

Asset specificity, uncertainty and frequency are the dimensions of transaction cost dealt with by Williamson (1975) (1981) ${ }^{\text {cvii }}$ (1985). Those three dimensions are important drivers in the formation of an organization, but the purpose of company (organization) declines as companies grow in terms of FIF and markets become abundant with FIFs, and the markets get to be utilized more for such activity as market trading of companies, specific assets, managers, and so on.

-Purpose of company from asset specificity perspectives:

In order to avoid the hold-up problems, specific human assets are enclosed within organizations so that the employee has to establish closed FIFs (both explicit and implicit) with the organization to decrease the relatively large transaction costs of specific assets (such as connection, mutual understanding, monitoring, and switching, etc.) and his/her bargaining power due to the specificity gets offset. The employee has to pay large switching costs when he/she desires to start a new transaction. The closed FIFs above include corporate culture, custom, policy, vision and trust between organization and employees. The closed FIFs make benefits for the employee as his transaction costs for his/her assets decrease instead of paying large costs for AHIFs including with other clients in the future and his/her asset efficiency increases. Those make the organization and the employee reciprocally dependent. When there are enough numbers of open FIFs so that they can transact freely through the market, there is less need for the dependence and enclosure. There is no need for organizations when open FIFs become established for all the transactions but it less likely to happen with specific assets such as managers (human specific assets) because the frequencies of trading specific assets are too low (it is too costly per transaction) to establish FIFs in the market. It is so with any kind of less standardized products and the discussion about human specificity above could be similarly applied to any other specific assets. The market is, therefore, utilized for more standardized products such as commodities. Although higher liquidity (substitutability) leads to higher efficiency of resource utilization, the preference of specific asset holders and users for closed FIFs and the higher initial costs for the FIFs impede the establishment of open FIFs and the shift to market from organization. 
-Purpose of company from uncertainty perspectives:

While transactions through market rely on FIFs, particularly contracts with minimum use of AHIFs, transactions in organization mainly depend upon AHIFs. As uncertainty such as unexpected (ad hoc) changes in demands, market institutions, governmental regulations, opportunistic behaviors, etc. can be handled easier by AHIFs ${ }^{9}$, organizations are more flexible than market in terms of handling both environmental and behavioral uncertainty. When FIFs are well established in the market and shared with lower costs and the transaction costs are sufficiently decreased, the market can handle uncertainties better. Decentralization of organization is the introduction of market mechanism in order to deal with the environmental and behavioral uncertainties which hierarchy never can.

-Purpose of company from high transaction frequency perspectives:

Between two entities which have frequent transactions, uncertain events will occur frequently such as occur between supervisor and worker in a factory, for which reason they resort to the special purpose institution in the company instead of the court (Milgrom and Roberts, 1992). Such frequently occurring problems should be solved through those fixed platforms that specialize in the development of the AHIFs. For transactions with high frequency, it is easy to establish closed FIFs in a company but it is also possible to resort to the special purpose institution existing outside if there is any. As long as the transactions with high frequency are considerably similar and there are plenty enough of FIFs related to solving the problem, even FIFs can handle the transactions instead of enclosing them within an organization to resort to AHIFs.

\section{STAGES of COMPANY GROWTH}

A company undergoes four stages of growth, namely: first, Spontaneous generation stage; second, Hierarchy stage; third, Decentralization stage; and forth, Networking stage. For a graphic representation of these stages of development, please see figure 8. Efficient utilization of resources through division of a company and interconnection of resources among companies advance by stages until companies are fully integrated into the market and all transactions are executed through the market.

\footnotetext{
9 As uncertainty is unexpected change in situations and/or of priorities on dimensions of evaluation, FIFs in specification, compensation, monitoring, switching are not likely to be designed in advance under uncertainties.
} 
Figure 8: Organization's Growth by Stages

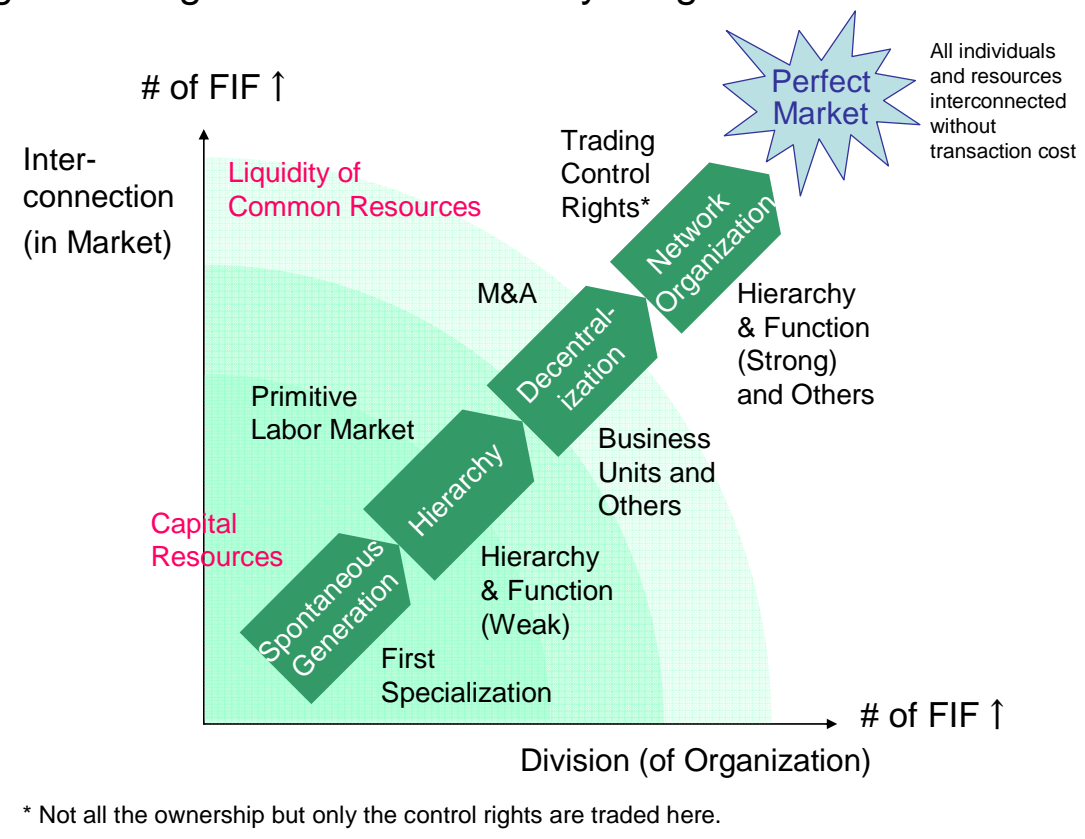

\section{1) SPONTANEOUs GENERATION STAGE}

A company normally originates from a group of people associated for a common purpose and led by a president who issues only AHIFs. Under this initial situation, FIFs do not exist yet inside the company (except the agreement that the president has all the residual control rights). The president and all the employees are consequently interconnected with ad hoc interfaces. Individual motivation and skills are more emphasized than institutional capabilities.

The first external FIF relating to the company is that which defines the ownership rights of a company as a separate entity with specialization capabilities. There already exist many social infrastructures in the market to achieve the interconnectivity of common (general purpose) resources. FIFs of social standards such as capital market rules and product standards interconnect companies to trade resources. Trading of resources advances as the number of standards increases. For the interconnection of specific resources, however, specific assets (such as human specific assets) and a company establish the relation-specific FIFs (both implicit and explicit) that help reduce the transaction cost between them. This is one of the most important purposes of company.

\section{2) HIERARCHY FORMATION STAGE}

The first internal FIFs are deployed for the purpose of allocating ownership or control rights 
(of issuing AHIFs) delegated by and exercised on behalf of the president ${ }^{10}$ to employees. Thus, AHIFs can be issued by the employees with ownership delegated more flexibly to increase the company's controllability. This is the main objective of this hierarchy formation stage. Ownership (in this case, residual rights and residual claims) is effective when contracts are incomplete, particularly when the company at this stage is incapable of forecasting and planning under uncertainty. The control rights in a company give the employees the ownership and the authority in a certain scope of work, which establish the hierarchical specialties consisting of managerial and functional specializations ${ }^{11}$.

The managerial specialization covers the area of managers, supervisors and operators, while the functional specialties include production, marketing, sales, personnel, accounting, etc. (functional specialties are divided by "quasi-interfaces" as defined in Chapter 5). Other additional FIFs are being deployed to replace AHIFs for reduction of transaction costs. All those deployed before entering the next stage are related with and support the hierarchical (managerial and functional) FIFs. The company is willing to expand its size, consequently increasing the number of transactions needed to finance all those FIF-related costs ${ }^{12}$.

Authority comes with the responsibility. Employees dedicate their outputs in exchange for obtaining the control rights. On the other hand, rewards such as fixed income and/or residual claims are compensated in relation to the volume of his or her authority and responsibility. At this stage, however, AHIFs still overwhelm FIFs (that is, interfaces are "weak" or less explicit, consisting of more AHIFs and fewer FIFs) and the ownership is not explicitly defined well. This is because the upper management adheres to AHIFs which secure their powers and positions and they also lack capabilities to design FIFs under uncertainty.

The hierarchical (managerial and functional) FIFs are "weak" (not explicit enough) to be socially standardized but can possibly be shared among companies and individuals to some extent. For instance, someone's experience as sales manager for three years secures his/her qualifications more or less. Interconnectivity in terms of human resources is achieved here not perfectly but only to serve and perform the functions of a human resources market in its early and primitive stage.

\footnotetext{
${ }^{10}$ His ownership is also delegated from the investors of the company.

${ }^{11}$ Hierarchy is naturally selected to organize complex systems as Simon (1969) ${ }^{11}$ designated. Another reason to select hierarchy as axis to divide a company is that there is no other useful axis yet. The nature of the business is initially homogeneous with the existence of a small number of clients and products---all of which are not as crucial as hierarchy at this stage.

${ }^{12}$ In other words, economy of scale due to the deployment of FIFs is sought and achieved.
} 
As the complexity (diversity) in external environment and internal resources increase, the disadvantages arise in terms of problems related to effectiveness of FIFs designed centrally. Environmental uncertainty increases as the company digests the original factors for success which have made the establishment and growth of the company possible. Monitoring the responsibilities of employees under increasing behavioral uncertainty becomes difficult and agency/influence costs increase. The vertical allocation of ownership does not clarify the source of problems in the complexly intertwined responsibilities of management vs. operation, creation vs. use of FIFs, etc. Those are difficult to break up and dissociated from one another. Likewise, these problems exist in the horizontal allocation of the responsibilities in manufacturing, marketing, sales, maintenance service, IT service, branding, advertisement, etc. Responsibilities over problems and contributions of achievements disperse widely across the participants. In order to deal with those disadvantages, the company needs more FIFs to perform decentralized or modular with effective self-evaluation functions.

\section{3) DECENTRALIZATION STAGE}

In the next and third stage of growth, in order to deal with problems of the previous stage, the company is decomposed into small but reasonably-sized modules. Usually a business unit (multi-divisional) organization ${ }^{13}$ structure is selected and the performance of these modules are evaluated by markets.

More explicit and simple ownership (authorities, responsibilities, and rewards) defined by "strong ${ }^{14 "}$ interfaces provides incentives for employees of discrete module that discourage rent-seeking behavior which incur both agency costs (between principal and agents) and influence costs (among peers) which account for a major portion of costs in hierarchical organizations (Collis and Montgomery, 1998) characterized by the previous stage. In particular, evaluation of profits generated (or delegation of the residual claims) encourages them to minimize those costs.

The size of decomposed modules is adjusted depending upon counterbalancing factors - the factors that favor large-sized modules requiring a great volume of transactions that finance FIF costs and low levels of monitoring costs. As FIF development capabilities are accumulated (including FIFs carried over from the previous stage) and those FIF costs are reduced, the size of modules can become smaller.

\footnotetext{
13 The company may be divided according to the nature of business, product, location, client segment, etc.

14 Meaning more explicit consisting of more FIFs and fewer AHIFs.
} 
The autonomy of business units is crucial here and the decomposition to smaller modules is pursued (under consideration of counterbalancing factors). First, the authority to control interfaces (both FIF and AHIF) with the external environment such as supplier relations (procurement in overheads and manufacturing), client relations (sales and marketing), potential employees relations (recruiting), etc. are delegated to the business units (more precisely, functional departments in the business units performing those functions). A headquarter module, however, may remain without division maintaining the interfaces in overhead functions such as public relations, investors/banks relations, alliance relations, branding (customer relations), inter-business unit relations because these need to be unified for efficiency. Even in this case, the direction towards decomposition of a company and liquidity of the resources will continue until a holding company system is formed and the discrete business unit has ultimate ownership ${ }^{15}$ with total access and integration into the market.

Profitability measure is used for the market evaluation of modules because it already exists free with accumulation of management know-how (accounting) as market standard. This achieves the interconnectivity in terms of business unit, namely, business units are hereby traded among companies for efficient utilization.

Up until this stage, uncertainties have increased because the company deals with more complexity of the external (and consequently internal) environment with its extended operation in a more matured market after its successes. The centralized decision making is effective as long as the market has little uncertainty in the previous stage, and market evaluation is needed to enable the company to satisfy the market needs, and to ensure the company's continued growth at this stage.

Obviously, the ultimate decomposition brings inefficiencies in the company caused by duplication of resources (mainly functions) which can possibly be shared among the modules (business units).

\section{4) NETWORKING STAGE}

In the last stage of the growth, modules (business units) are decomposed by strong interfaces of function and deploy FIFs necessary for interconnecting each other. Any kind of interconnection of resources (load balancing and functional distribution) which produces better efficiency than that obtained by a single independent operation of discrete module will

15 The holding company has only investors' ownership. 
be sought, agreed and deployed. Examples are sharing the functions of manufacturing, sales, support services, IT operation, logistics, accounting, general administration, personnel, public relations, investor relations and branding, including external outsourcing services. In the case of IT operation, a whole or a portion of data storage discs, servers, maintenance staffs and/or development teams could be shared. This networking of resources is possible with the introduction of FIFs that allows trading of control rights of resources without granting full ownership entitlements.

The interfaces of hierarchy in the business units should be strong (explicit) because the transactions are with other functional departments existing externally. The more FIFs (strong interfaces) of function exist, the more possible interconnection with other functions becomes. The decomposition advances further than the previous stage on account of interconnectivity. Being able to depend on resources of others and to exist without the full line of functions, smaller modules with fewer functions than business units evolve in the process.

As long as specific assets are considered, the preference of specific asset holders and users for closed FIFs and the higher initial costs incurred at the FIFs impede the establishment of open FIFs and the shift to market from organization, as previously discussed. At this stage, however, the decomposition and interconnection continue until all organizations become decomposed and all individuals interconnect perfectly and there is no need for organizations to exist. All the way up to this final goal, the decomposition of organizations and the interconnection in the market co-evolve.

As the number of FIFs increase given that those are properly designed and committed, the company becomes capable of handling more complicated situations, namely, a bigger volume of resources, customers and outcomes with diversities. The deployments of all those FIFs require a higher level of ability for the company to forecast and plan for uncertain events, and to create, to use, to maintain and to change FIFs. Otherwise, the costs increase and the efficiencies decrease. Capabilities related to FIFs should be carried over from the previous stages and furthermore the company should continue to strengthen them so that FIFs are utilized more efficiently. The company also can properly utilize FIFs existing externally with lower costs such as globally, industrially and regionally standardized interfaces. The adoption of those open FIFs enables the utilization of external resources. The company is able to add and/or delete modules, for instance, selling their overhead service departments and replacing the functions with outsourcing companies. The larger the number of valuable external resources is available in the network era, the less the company needs to depend upon its 
internal resources. The company starts concentrating on a single core competence which interconnects closely with others. This expands the demand for and the establishment of open FIFs. Thus, the network structure initiates a virtuous circle of externalities involving a greater number of open FIFs and a greater volume of interconnections.

-Transition by stages:

Transition in the growth of a company is brought about by the deployments of FIFs in organization and market. FIFs have the dual functions of dividing and interconnecting resources. An organization is decomposed and as a result of the increase of interconnectivity, the market mechanism becomes more utilized. The transition evolves by stages, not moderate and continuous, on account of political conflicts and frictions in organizations.

After the formation of a company, in the second stage of hierarchy, the first and basic internal FIFs for hierarchical (managerial and functional) allocation of control rights are introduced for the establishment of AHIFs related capabilities and specialization. As those are the first rules for the company, they are likely to be rejected by the president who has been freely and flexibly making decisions and the employees who have been only following their president instead of making own decisions. Once the rules are accepted and implemented properly, centrally-developed FIFs increase in number.

Because ownership (responsibility and authority) becomes vague as the internal and external complexity increases and it becomes difficult to monitor outcome under increasing uncertainties, FIFs of business units are deployed for the more explicit ownership and effective decision making by using market evaluation in the third stage of decentralization. As this is the transfer of authority and power, this transition encounters the barriers very often.

Once the autonomy of business units becomes more established, FIFs are deployed for interconnection of modules to utilize resources efficiently in the fourth stage of networking. Market standards may be adopted here for introduction of outsourcing to substitute a whole or a portion of the functions. It can be seen that the departments to be regulated by FIFs or substituted will object to this transformation.

The reasons for the opposition to these transitions are threats to the reduction of rewards. First, the employees, departments, and divisions may be replaced under market mechanisms, and second, FIFs eliminate AHIFs which involve authority and power, and wealth that people adhere to. Rejections come even from the president in the first stage, from upper management 
in the second stage, and from the departments controlled by new FIFs in the third stage. The need to deal with those political conflicts requires that the transitions be drastic and implemented in stages, not moderate or continuous. There are also severe psychological rejections from employees who can not catch up with the shift of organizational environments. The shifts from first stage to second, from second to third, and third to fourth strengthen employees' independence, freedom, and responsibility on account of advancing division, and competition and substitution on account of advancing interconnection. These are welcome by some of them and incentivize those with a sense of independence and a potential of capabilities but not always easy to comprehend in the case of others.

A company may fail to proceed to the next stages by reason of the rejections if the FIF-related capabilities of the company are ill-developed or immature. For instance, a company which invests in huge amount of resources without the good capabilities of hierarchical FIFs will not be able to establish the FIFs properly and will easily regress to the previous stage. The same failure will happen to a company which tries to advance to the third stage without the capabilities of vertical division (delegation of authorities and/or execution of responsibilities).

On the contrary, a company's growth may start from the second, third or even fourth stage leapfrogging the previous stages if it has already accumulated the FIFs and FIF-related capabilities. For instance, a company can start from the third stage if it has mature capabilities of creating and using hierarchical and business unit FIFs. A company can also start from the fourth stage such as venture start-ups in Silicon Valley that have developed very strong capabilities related to FIFs by virtue of their rich and abundant logical thinking skills ${ }^{16}$. As open FIFs increase in the market, it reduces the costs of the deployment of FIFs and the access to external resources, and it facilitates growth to start from the later stages.

At any rate, the dynamic analysis of market and organization in terms of efficiencies with establishments of FIFs should be pursued to a greater extent. The market without FIFs is less efficient than organizations and the opposite is true. Market and organization grow with FIFs and their efficiency varies. Market or organization issue should be considered with the variable of FIF in terms of efficiency. FIFs in organizations will be standardized in markets. It brings about the more efficiency of resources utilization when developing FIFs. Therefore, the growth of organizations results in the growth of markets. They co-evolve and the process continues until the markets become perfect.

\footnotetext{
${ }^{16}$ Logical thinking skills to setup the context of claims are strongly required when developing FIFs.
} 


\section{STANDARDIZATION of FIF}

Considering that standards contain various interface attributes as below, there is a need to carefully analyze the concept and implications of standards in interface researches. A good/service is defined as a standard when any (or both) of the following is satisfied: (1) it is utilized by a dominant number of users, (2) it functions as a common interface (FIF).

The presence of a dominant number of users establishes credibility or reputation, which is also considered as an FIF of a quality guarantee system. Such an interface shared by a large number of users is likely to decrease the cost and further increase the number of users. The overwhelming number of users also further enhances the value of the product.

Standardization activities such as the Internet initiatives have considerably interconnected resources, decreased costs of transaction (information costs in particular), and have resulted in consumers buying from one particular supplier, accelerating a virtuous circle of economies. All these positive feedbacks enable such a supplier of a good/service to increase its market share. Only standardized goods/services are able to win or survive market competition being known as a "Winner takes all" phenomenon.

Standardizing goods/services equals increasing the market share of one or more of the interfaces (FIFs) of the goods/services, such as the user interface, connecting or communicating interface, mechanical interface, information gathering interface, etc. When these attributes of the good/service are decomposed (divided) with commonality and interconnected (shared) with others for further commonality, they gain the market share and become the standard. The decomposition of good/service to modules of attribute decreases its specificity (increase its commonality) and enables fungibility of the module on account of the interconnection.

Meanwhile, companies also integrate interfaces which have been established in market. "It was not until the 1870s', with the completion of the modern transportation and communication networks - the railroad, telegraph, steamship, and cable - and of the organizational and technological innovations essential to operate them as integrated systems, that materials could flow into a factory or processing plant and finished goods move out at a rate of speed and volume and with the precise timing required to achieve substantial economies of throughput." (Chandler and Hikino, 1990) The integration of all those similar interfaces as a newly developed network may have decreased the transaction costs drastically. 
Thus, the decomposition and the interconnection of goods/services can be discussed under the same framework of company growth which explains that "transaction cost economies are realized at the expense of scale economies or scope economies" (Williamson, 1985) and "( $t$ )he costs of such transactions are reduced by a more efficient exchange of goods and services between units, whereas the economies of scale and scope are closely tied to the more efficient use of facilities and skills within such units." (Chandler and Hikino, 1990) Let us explain.

As figure 9 shows, the division with commonality produces higher frequency of occurrence, less specificity, higher specialization, and the resulting economies of scale. In the case of organizations, this division also provides greater incentives with more explicit ownership to the organizational unit. The interconnection of all those divided units equals the standardization and consequently the decrease of transaction costs for trading modules on account of the deployment of commonly shared FIFs. This efficiency improvement is deemed

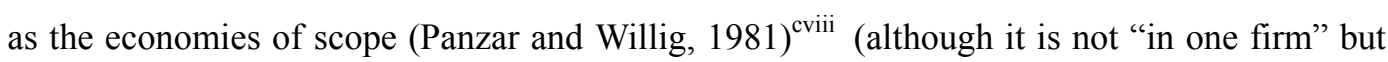
among many) of the modules.

\section{Figure 9: Efficient Utilization of Resources by Deployment of FIFs or Economies of Scale and Scope}

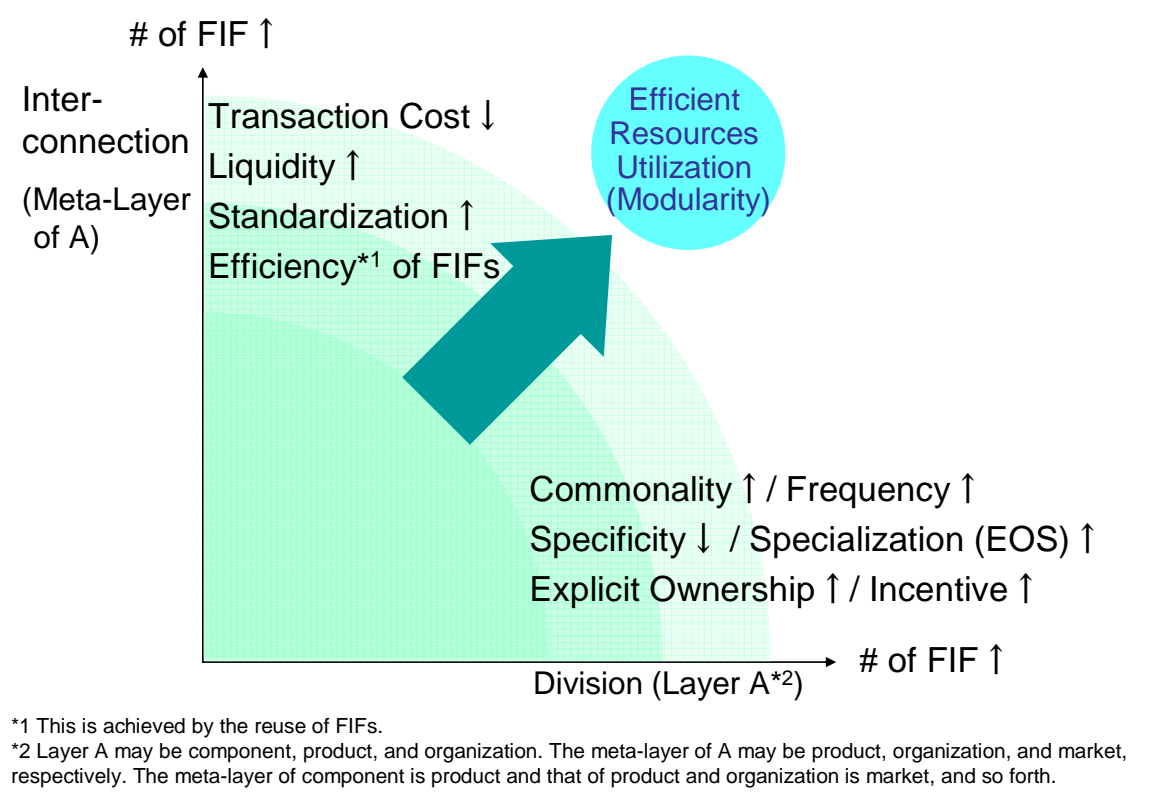

Increasing FIFs for division in organization should be integrated and standardized in market for interconnection. The standardization cost of FIF is easily financed by the consequently increased number of transactions. The accumulation of FIFs continuously reduces the cost per 
transaction and increases the efficiency. The organization evolves with the increasing FIFs and so does market. They co-evolve until ultimately efficient utilization is achieved for all the resources.

The more strategically important a product's acquisition of a standard position in the market becomes, the greater the reduction in price and in exclusivity of use is needed to increase its market share. Patent pools such as MPEG2, the $3 \mathrm{G}$ technologies of mobile phones, and the next generation DVD require the patent holders to keep the licenses open putting the first priority on the dissemination and standardization of technologies. For the same reason, recent IT products with platform functions such as JAVA, XML, LINUX, etc tend to be open.

The more the prices decrease, the less conspicuous the direct benefits of acquiring a standard become. Successful standardization of FIF yields, however, some indirect benefits by establishing and utilizing other closed FIFs on the standardized FIF. The advantage of being more familiar with the FIF (technologies in particular) compared to other competitors allows the business utilizing FIF on product/business development to layer over the standardized FIFs. This is widely known as the first mover advantages. The opportunities to develop a business in services to further reduce transaction costs such as in consulting, integration and education are also included in indirect benefits. The brand developed with the achievement of standardization also supports any kind of related business developments over the standardized FIF.

The requirements to open FIFs change the corporate strategies fundamentally.

\section{MODULARITY}

-The degree of modularity:

"Clearly there are degrees of connections, thus there are graduations of modularity." (McClelland and Rumelhart, 1995) ${ }^{\mathrm{cix}}$ (Baldwin and Clark, 2000)

Given that Williamson (1985) indicated that asset specificity, the most important dimension of transaction cost makes assets less redeployable, transferable, and fungible, thus requiring organizational governance, the concept of modularity has a close relationship with transaction cost economics. Its widely accepted definition: "a module is a unit with elements that are relatively tightly and coherently coupled/connected inside and relatively loosely and weakly outside" actually states the degree of substitutability, redeployability, transferablitiy and fungibility. 
While this research focuses on issues relating not only to inter-modules (addition and subtraction) matters but also to intra-module (incentive and specialization) matters, issues inside modules were not major topics in past module researches presumably because modules are often recognized as limited to non-human entities such as components. In this research, interfaces of artifacts, such as components, parts, softwares, and organizations are deemed intended for the regulation of human development activities. For example, a bolt is a product manufactured by a module with autonomy under regulation of FIFs. The module is interactive with other modules that manufacture nuts with the FIFs. In this sense, a broad definition of modules may also include goods produced by a module in order to accord with widely-accepted recognition. Compared to the case of modules with strictly mechanical interfaces, modular units such as human resources have more transaction interfaces such as information search, negotiation, contracting, ordering, payment, and monitoring and the interface structure is much more complicated.

Where FIFs are established among entities, transaction costs for subtraction of resouces (breakdown of an old relataionship) within a substitution and for addition of resouces (start of a new relationship) are basically lower. Accordingly, even specific assets do not require organizational governance as long as they interact through FIFs shared commonly with the subsutitutes in market. But the effects vary depending upon who owns the FIF. If you own the FIF, it is applicable with your new substitutes with the possibility of the market share of the $\mathrm{FIF}^{17}$. It is applicable only with the users of FIF. If your partner owns the FIF, it is not applicable to your subsutitutes. ${ }^{18}$ FIF which is relation-specific to the old partner is not applicable either. A market standard FIF is applilcable as much as the market share of the FIF. The ownership of FIF determines the direction of fungibility. This is so even with mechanical component modules. Component modules can be substituted on a platform module but not the other way around inasmuch as the interface belongs to the platform module, not to the components.

In order to preclude use by competitors of your own FIF, two approaches must be adopted to hinder FIF from being copied and reproduced (even assuming that copying is allowed). One approach involves material composition (such as in ceramics and pharmaceuticals) and API ${ }^{19}$ in binary code (not in source code). The second includes patents and trade secrets as well as processing knowhows.

\footnotetext{
${ }^{17}$ Your FIF may be refused by your substitute. The possibility of acceptance is the market share of the FIF.

${ }^{18}$ FIF owned by your partner which you can use should be classified as your own FIF.

19 Application Programming Interface is agreed rules to access the functions of software.
} 
There are many transaction interfaces within one transaction as we have been discussing. Even the interface of product specification can be decomposed to many sub-interfaces, such as physical, mechanical, electrical, software (API), production process, etc. All those can be independently owned. Therefore, the asset specificity is multiple and unilateral ${ }^{20}$. The discussion of FIF applicability above should be discussed with all the independent multiple interfaces, and the integration of power balance determines the total dyadic power balance. ${ }^{21}$

The ownership issue of various interfaces is, however, basically a bargaining power issue. Transaction conditions such as the site of exchange, the way of order/payment, the level of product customization can be deemed as price negotiation. If you have bargaining power, you can dominate all the conditions. So the only single issue is if you have bargaing power or not. An entity with scarce resource ${ }^{22}$ is likely to own FIF using its bargaining power, or at least it will use market FIFs to secure fungibility. Securing fungibility determines the ultimate barganing power. Therefore, resource scarcity and FIF ownership are supposed to be related.

Japanese companies had not have ensured fungibility but established long term relationships instead. This can be explained by their lack of capabilities to design or develop explicit FIFs and their dependence upon implicit FIFs (such as coustoms and trust) which were never applicable to the potential substitutes.

Independence of entity is usually defined as self-governance, self-enforcing, or ultimate authority, and those are also deemed as the capability of substituting partners. Let us define the power of entity as fungibility, price barganing power, and independence. And modularity is deemed as the power of entity. The degree, the relativity or the extent of modularity should be measured for analysis, and these hypotheses must be quantitatively verified in future research.

-Progress of modularity in industry structure:

Modularity evolves within the product life cycle of final products. Think of the setup of an industry having parts manufacturers and parts assemblers. An example is shown in figure 10. When a final product (automobile or computer, for instance) is introduced into the market in

\footnotetext{
${ }^{20}$ While, in the TCE researches, dependent bi-laterality such as mutual lock-in has been discussed, uni-laterality is focused here. Although asset specificity at discrete interface is unilateral, the integration of interfaces determines the total bi-laterality. This analysis becomes possible due to the introduction of interface concept and the disintegration of relationship.

21 A popular way of acquiring power by holding partner's stocks is equal to owning residual rights, which is similar to the deployment of organization.

${ }^{22}$ Resource scarcity depends on discrete module, not the structure of module, therefore the unrelated variable should be neglected here.
} 
the first stage of the product life cycle, the assembler designs the product and begins to subcontract with a part manufacturer. The assembler holds the intellectual property rights and requires the subcontractor technological cooperation under an exclusive arrangement. As the product generates profits gradually, the number of competitors increases. In order to deal with fiercer competition, the assemblers put pressures on the subcontractors to reduce the costs and venture into opening subcontracting relationships with other parts manufacturers. As the relationships become open among the assemblers and the parts manufacturers, some parts manufacturers deploy a module structure to handle the cost pressures and various specification needs from the assemblers, while the others stick to their integral or custom-made structure as in the past. One of the part manufactures successfully satisfies the specifications of the assemblers and is able to increases its market share. Once a product becomes closer to the market standard position, economies of scale are allowed to operate, the product is built in assemblers' design processes as a standard (becomes a FIF) and the market share further increases reinforcing the standardization toward monopoly. The price of a standardized part raises and overcomes the value added of the assemblers. Modularity in industry structure advances as various kinds of FIFs are disseminated in the market.

Figure 10: Progress of Modularity in Industry Structure

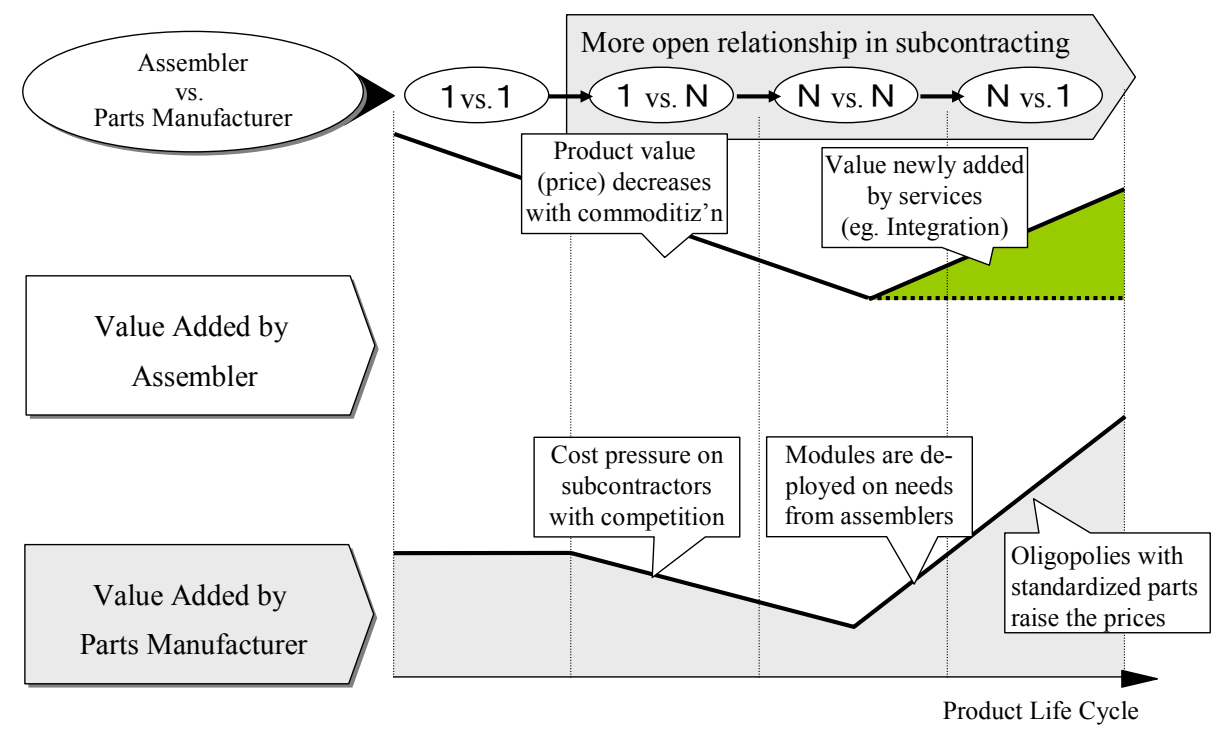

Transition in the computer industry is a typical example. IBM used to have a strong inclination towards vertical integration up until the 1980s. All the parts including CPU, printer, circuit board, OS, application software, etc. were produced in-house and IBM had monopolized the market. In 1981, however, IBM introduced IBM PC (IBM Personal 
Computer model 5150) outsourcing many parts including OS and CPU to compete with PC manufacturers such as Apple, Tandy RadioShack, Commodore and others. The value added was overtaken by Microsoft and Intel afterwards and IBM fell into a near-death situation after giving its counsel table of the antitrust suit to Microsoft. In the early 1990s, IBM appointed Louis V. Gerstner, Jr. as CEO who turned around IBM to an integration service company successfully. In order to compete with a monopolistic behemoth, small players need to cooperate in sharing the opposing open FIFs that have proceeded with the modularity process industry-wide. There have been plenty of open FIFs in the computer industry including networks, bus interfaces, peripheral connections, data storage, and all the interface technologies of the Internet.

-Modularity design and logical thinking:

In psychology and cognitive science, after Fodor (1983) argued that the mind is composed of modules, module structures have attracted attention such as in visual processing (Marr, 1982), in much of higher cognition and intellectual skill (Gardner, 1983), in language processing (Jackendoff, 1997), and in musical cognition (Lerdarl and Jackendoff, 1983). Modularity design and logical thinking have similar aspects too as argued by Pinker (1997) ${ }^{\mathrm{cx}}$, Fodor $(2000)^{\text {cxi }}$, and Carruthers $(2004)^{\text {cxii }}$. Let us define logical thinking as a combination of inductive and deductive processes. Through the former, the common elements are extracted as a module (and related interfaces) and the latter makes the extracted module interact with other modules (through the interfaces) consequently producing applications of the extracted module. In the process of designing modules where common elements are extracted and integrated into a new module, interfaces should be designed to permit and support proper interaction among modules. Although modularity is applied mainly to product design and logical thinking to information processing, both are the decomposition of a complex phenomenon into modules which have common elements and have interfaces to interact with other modules for the purpose of efficient utilization of resources.

\section{SYSTEM/INFORMATION TECHNOLOGY RELATED ISSUES with POSSIBLY WIDER}

\section{APPLICATIONS}

-IT Standards such as the Internet protocols, XML and XML related standards:

IT including the Internet functions as transaction interface in market or organization ${ }^{23}$. FIFs have continuously been developed on the Internet and have contributed to the reduced costs of various kinds of transactions as a consequence. XML (eXtensible Markup Language) allows

\footnotetext{
${ }^{23}$ Information technologies deal with production of information as resources, besides transaction (information processing) of physical objects (including information as resources) and transportation of information as resources.
} 
computers (software) to recognize the data and to communicate, interact, and collaborate with each other. Many FIFs such as Rosettanet and ebXML which rule the market transactions are under development on XML. Other examples of standards include EAI (Enterprise Application Integration), Utility Computing technologies, and P2P protocol.

\section{-Open Source Software:}

The software with GPL (General Public License) is open source software. As GPL makes the software developers to redistribute their software without charge, there is almost no negotiation needed for the transaction of the software. That with other various FIFs such as versioning systems, file up/downloading, bug tracking systems, etc. reduces the transaction costs, enables value added easily and disseminates the software among software developers.

-Platform:

Meyer \& Lehnerd (1997) ${ }^{\text {cxiii }}$ define a product platform as "a set of subsystems and interfaces that form a common structure from which a stream of derivative products can be efficiently developed and produced". A module which functions as platform has unilateral fungibility as other modules can be substituted while the platform can not. The best example is OS (operating system) of computers which works as a platform for a group of application software interoperation. Platform is a very basic shape of module structure and as the idea of modularity has disseminated, it has appealed to many researchers such as Robertson \& Ulrich $(1998)^{\text {cxiv }}$.

-Network:

Network is a multi-layered complex of interfaces including physical protocols (electric and mechanical), data formats, networking rules (routing and addressing), transportation rules (data compression and error correction), data transmission control rules, presentation format (font, multimedia, etc.) and application program interfaces and a huge number of business rules. As described in the section "Benefits of FIF", interfaces determine the qualitative attributes (type and quality) and quantitative attributes (volume and velocity) of flow on network and assign the input, output and function of discrete module. Thus, network could be defined as a nexus of interfaces. Transaction costs incurred in the interfaces of development, operation, and switching are an impediment or friction to the flow. Although the interface model of this research only deals with the dyad relationship, because the information in the network outside the dyad is searched and input, all triad relationships are able to be described by this model. 
-System:

System is composed of the rules of interaction of elements (and the interacting elements themselves are referred to as well). Elements are transacting with each other through the interfaces (see figure 11). Interfaces determine the attributes of flows qualitatively (type and quality) and quantitatively (volume and velocity). Whatever module has capabilities and however it has capacity, interfaces regulate the outputs. This assignment is applied for any kind of flow of resources such as material, intermediate product, information, rewards, etc.

Figure 11: Function of Interfaces

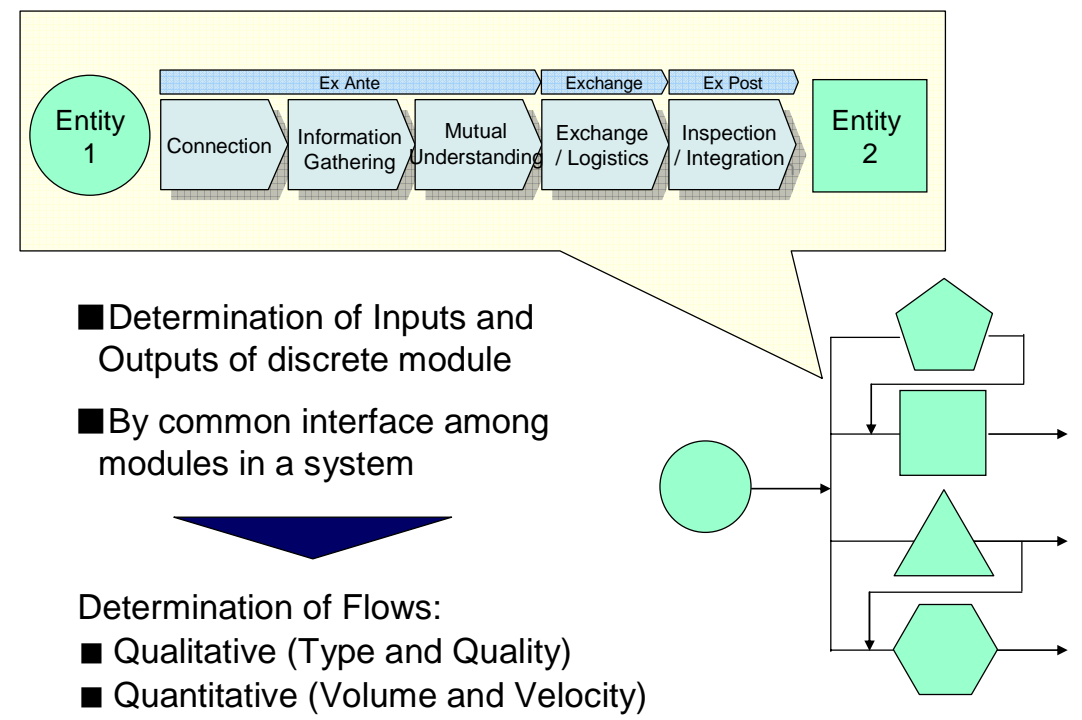




\section{Concluding Remarks: \\ The importance of interfaces studies in network environment}

There are many emerging aspects which justify the increasing importance of transaction interface studies. After the Internet dissemination, the potential of utilizing external resources and the efforts to interconnect those by establishing social FIFs increase in a wider-ranging and deeper scale. Obviously the interrelated structure such as that in the Silicon Valley companies has been successfully exhibiting greater competitive advantages. Furthermore standardizing FIFs becomes the important strategic target as the acquisition of standard becomes the key for success. As the fiercer competitive situation requires companies to change more rapidly at lower cost, FIFs have to be utilized more and more, especially under a situation in which the transaction costs represent a major portion of total marginal costs (or the total costs) in companies and markets involving software, information and knowledge -the duplication and transportation costs of which are smaller and therefore have a greater effect on the value of goods. FIF is the only institutional way to decrease the costs. Although there are risks to fixing interfaces, the companies that take more risks in concentrating their investments win the game.

Moreover, companies facing uncertainty come around to prefer the adoption of a market mechanism internal to the organization, such as modularity (decentralization and networking) rather than hierarchy. Incentivization or the grant of greater ownership possession to each module approximates markets, and at the same time, FIFs interconnecting the modules increase the efficiency. FIFs are developed for division and interconnection in the interest of utilizing resources further to the maximum. Organization and market tend to fuse and the border becomes blurred attributable to FIFs.

The decomposition of organizations and markets enables dynamic analyses and they appear to co-evolve and ultimately integrate. Another decomposition of transaction relationship reveals the complicated structure of partnership involving such realities as power, independence and, of course, modularity. Fungibility of module is explained by the same variable as specificity of asset. All those researches will become possible through further studies of the variable: transaction interface. As it is the smallest unit of economic activities, measuring it especially after the relatively large cost of measurement has been surmounted, become possible, with the result that interface studies attain the status of being in a position to offer a key to the analysis of the modern economic phenomena. 


\section{References:}

i Coase, R. H. (1937), “The Nature of the Firm," Economica, 2(1), pp. 386-405.

ii Williamson, O. E. (1985), The Economics Institutions of Capitalism, Free Press.

iii Economides, N. and S. Salop (1992), "Competition and Integration among Complements, and Network

Market Structure," The Journal of Industrial Economics, 15(1), pp.105-122.

iv Milgrom, P. and J. Roberts (1992), Economics, Organization and Management, Prentice Hall.

v Daft, R. L. and A. Y. Lewin (1993), "Where are the theories of the 'new' organizational forms? An editorial essay," Organization Science, 4(4), pp. i-vi.

vi Sanchez, R. (1995), "Strategic Flexibility in product competition," Strategic Management Journal, 16, pp. 135-159.

vii Ashkenas, R., D. Ulrich and S. Kirr.(1995), The boundaryless organization; Breaking the chains of organizational structure, Jossey-Bass.

viii Snow, C., R. Miles and H. J. Coleman (1992), "Managing $21^{\text {st }}$ Century network organizations," Organizational Dynamics, 20(3), pp. 5-20.

ix Schilling, M. A. (2000), "Toward a general modular systems theory and its application to interfirm product modularity," Academy of Management Review, 25(2), pp. 312-334.

x Clark, K. and T. Fujimoto (1990), "The Power of Product Integrity," Harvard Business Review,

November-December, pp. 107-118.

xii Benham A. and L. Benham (2000), "Measuring the costs of exchange," in Ménard, C. (ed.), Institutions, Contracts and Organizations: Perspectives from New Institutional Economics, Edward Elgar, pp. 367-375.

xiii Wallis, John J., and Douglass C. North (1986), "Measuring the Transaction Sector in the American Economy, 1870-1970," in Engerman S.L. and R.E. Gallman (1986), Long-Term Factors in American Economic Growth, Studies in Income and Wealth, 51, University of Chicago Press. pp. 95-161.

xiv Sandler, T. and J. Cauley (1977), "The Design of Supranational Structures: An Economic Perspective," International Studies Quarterly, 21, pp. 251-276.

${ }^{x v}$ Keohane, R. O. (1984), After Hegemony: Cooperation and Discord in the World Political Economy, Princeton University Press.

xvi Yarbrough, B. and R. M. Yarbrough (1990), "International Institutions and the New Economics of Organization," International Organization, 44, pp. 235-259.

${ }^{x v i i}$ Downs, G. W. AND D. M. Rocke (1995), Optimal Imperfection? Domestic Uncertainty and Institutions in International Relations, Princeton University Press.

xviii Kang, D. C. (1995), "South Korean and Taiwanese Development and the New Institutional Economics," International Organization, 49, pp. 555-587.

${ }^{x i x}$ Lake, D. A. (1999), Entangling Relations: American Foreign Policy in Its Century, Princeton University Press.

${ }^{x x}$ Moravcsik, A. (1999), “A New Statecraft? Supranational Entrepreneurs and International Cooperation,” International Organization, 53, pp. 267-302.

xxi Wallaner, C. (2000), "Institutional Assets and Adaptability: NATO after the Cold War," International Organization, 54, pp. 705-736.

xxii Weber, K. (2000), Hierarchy amidst Anarchy: Transaction Costs and International Choice, State University of New York Press.

xxiii Lipson, M. (2004), "Transaction Cost Estimation and International Regimes: Of Crystal Balls and Sheriff's Posses," International Studies Review, 6(1), pp. 1-20.

xxiv Polski, M. (2001), "Measuring Transaction Costs and Institutional Change in the U.S. Commercial Banking Industry.” Institute for Development Strategies Discussion Paper, ISSN 01-3. January.

${ }^{x x v}$ Eggertsson, T. (1990), Economic Behavior and Institutions, Cambridge University Press.

xxvi Dahlstrom R. and A. Nygaard (2005), "Measurement of Transaction Costs and Falsification Criteria:

Toward Future Directions in Empirical Research on Transaction Costs Theory," in James, Jr. F. S. (ed.), New Ideas in Contracting and Organizational Economics Research, Nova Science Publishers, pp. 89-103.

xxvii Coase, R. (1960), "The Problem of Social Cost," Journal of Law and Economics, 3, pp. 1-44.

xxviii Alchian, A. A. and S. Woodward (1988). "The Firm is Dead; Long Live the Firm. A Review of Oliver E. Williamson's The Economic Institutions of Capitalism." Journal of Economic Literature, 26, March, pp. 65-79.

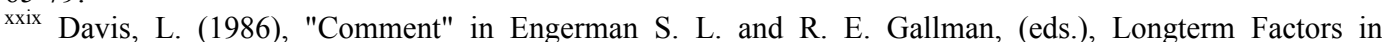
American Economic Growth, Studies in Income and Wealth, 51, University of Chicago Press.

${ }^{\mathrm{xxx}}$ Matthews, R. C. O. (1986), "The Economics of Institutions and the Sources of Growth," Economic Journal, 96, pp. 903-918.

xxxi Barzel, Y. (1989), Economic Analysis of Property Rights, Cambridge University Press.

xxxii Eggertsson, T (1990), Economic Behavior and Institutions, Cambridge University Press.

xxxiii Chandler, A. D. with the assistance of T. Hikino (1990), Scale and Scope, The Belknap Press of Harvard University Press. 
xxxiv Furubotn, E. G. and R. Richter (1997), Institutions and Economic Theory: The Contribution of the New Institutional Economics, The University of Michigan Press.

xxxv Vannoni D. (2002), "Empirical Studies of Vertical Integration: The Transaction Cost Orthodoxy”, RISEC, International Review of Economics and Business, 2(1), pp.113-141.

${ }^{x x x v i}$ North, D. C. (1990), Institutions, Institutional Change and Economic Performance, Cambridge University Press.

xxxvii Baldwin, C. Y. and K. B. Clark (1997), "Managing in an age of modularity," Harvard Business Review, September-October, pp. 84-93.

xxxviii Schilling, M. A. (2003), "Modularity in Multiple Disciplines - Commentary on Toward a General Modular Systems Theory," in Garud, R., A. Kumaraswamy and R. N. Langlois (eds.), Managing in the Modular Age: Architectures, Networks and Organizations, Blackwell Publishing, pp. 203-214.

xxxix Fodor, J. A. (1983), The Modularity of Mind, MIT Press.

${ }^{x l}$ Marr, D. (1982), Vision: A Computational Approach, Freeman.

xli Gardner, H. (1983), Frames of Mind: The Theory of Multiple Intelligences, Heinemann.

xlii Jackendoff, R. (1997), The Architecture of the Language Faculty, MIT Press.

xliii Lerdarl, F. and Jackendoff, R. (1983), A Generative Theory of Tonal Music, MIT Press.

xliv Garud, R. and A. Kumaraswamy (1996), "Technological designs for retention and reuse," International Journal of Technology and Management, 11, pp. 883-891.

xlv Ulrich, K. T. (1995), "The role of product architecture in the manufacturing firm," Research Policy, 24, pp. 419-440.

xlvi Baldwin, C. Y. and K. B. Clark (2000), Design Rules, MIT Press.

xlvii MacDuffle, J. P., K. Sethuraman and M. L. Fisher (1996), "Product Variety and Manufacturing Performance: Evidence from the International Automotive Assembly Plant Study," Management Science, 42(3), pp. 350-369.

xlviii Robertson, D. and K. T. Ulrich (1998), "Planning for Product Platforms," Sloan Management Review, Summer, pp. 19-31.

xlix Thonemann, U. W. and M. L. Brandeau (2000), "Optimal Commonality in Component Design," Operations Research, 48, pp. 1-19.

${ }^{1}$ Kamrani, A. K. and S. e. M. Salhieh (2002), Product Design for Modularity, Kluwer Academic Publisheres.

${ }^{\text {li }}$ Langlois, R. and P. Robertson, (1992), "Networks and innovation in a modular system: Lessons from the microcomputer and stereo component industries," Research Policy, 21, pp. 297-313.

lii Feitzinger, E. and H. L. Lee (1997), "Mass Customization at Hewlett-Packard: The Power of Postponement," Harvard Business Review, January-February, pp. 116-121.

liii O'Grady, P. (1999), The Age of Modularity, Adams and Steele Publishing.

liv Christensen, C. M., M. Raynor and M. Verlinden (2001), "Skate to Where the Money Will Be," Harvard Business Review, November-December, pp. 73-81.

lv Meyer, M. H. and A. P. Lehnerd (1997), The Power of Product Platforms, The Free Press.

${ }^{\text {lvi }}$ Lee, H. L. and C. S. Tang (1997), "Modelling the Costs and Benefits of Delayed Product Differentiation," Management Science, 43(1), pp. 40-53.

lvii Loch, C. H., C. Terwiesch and S. H. Thomke (2001), "Parallel and Sequential Testing of Design Alternatives," Management Science, 45(5), pp. 663-678.

lviii Worren, N., K. Moore and P. Cardona (2002), "Modularity, Strategic Flexibility, and Firm Performance: A study of the Home Appliance Industry," Strategic Management Journal, 23, pp. 1123-1140.

lix Randall, T. and K. T. Ulrich (2001), "Product Variety, Supply Chain Structure, and Firm Performance: Analysis of the U.S. Bicycle Industry, Management Science, 47(12), pp. 1588-1604.

lx Sanchez, R. and J. Mahoney, (1996), "Modularity, flexibility, and knowledge management in product and organizational design," Strategic Management Journal, 17, pp. 63-76.

lxi North, D. C.(1997), "Transaction costs through time," in Ménard, C. (ed.), Transaction Cost Economics, Edward Elgar, pp. 149-160.

lxii Mill, J. S. (1857), Principle of Economics, $4^{\text {th }}$ Edition, Parker.

lxiii Collis, D. J. and C. A. Montgomery (1998), Corporate Strategy, McGraw-Hill.

Ixiv Alchian, A. A. and H. Demsetz (1972), "Production, information costs, and economic organization," American Economic Review, 62, pp. 777-795.

${ }^{\mathrm{Ixv}}$ Baker G. P. and Hubbard T. N. (2001), "Empirical Strategies in Contract Economics: Information and the Boundary of the Firm”, American Economic Review, 91(2), pp.189-194.

lxvi Ménard. C. (1996), "Internal characteristics of formal organizations," in Ménard, C. (ed.), Transaction Cost Economics, Edward Elgar, pp. 30-58.

Ixviii Furubotn, E. G. and R. Richter (1997), Institutions and Economic Theory: The Contribution of the New Institutional Economics, The University of Michigan Press.

lxix Aggarwal, N. and E. Walden (2005),"Standards Setting Consortia: Transaction Cost Perspective," Proceedings of the $38^{\text {th }}$ Hawaii International Conference on Systems Science - 2005.

lxxvii Langlois, R. (1992), External economics and economic progress: The case of the microcomputer 
industry. Business History Review, 66, pp. 1-50.

lxxviii Sanchez, R. (1995), "Strategic Flexibility in product competition," Strategic Management Journal, 16, pp. $135-59$

Ixxix North, D. (1981), Structure and Change in Economic History, Norton \& Company.

Ixxx Aghion, P. and J. Tirole (1997), "Formal and real Authority in Organizations," Journal of Political Economy, 105(1), pp. 1-29.

lxxxi Baker, G., R. Gibbons and K.J. Murphy (1999), "Informal Authority in Organizations," Journal of Law, Economics and Organization, 15(1), pp. 56-73.

Ixxxiv Smith, A. (1776), An Inquiry into the Nature and Causes of the Wealth of Nations, Book I, Methuen and Co., Ltd, Chapter I.

lxxxv Anderson, J, C. (1995), "Relationships in Business Markets: Exchange Episodes, Value Creation and

Their Empirical Assessment," Journal of the Academy of Marketing Science, 23 (Fall), pp. 346-350.

Ixxxvi Cannon, J. P. and C. Homburg (2001), "Buyer-Supplier Relationships and Customer Firm Costs," Journal of Marketing, 65 (January), pp. 29-43.

lxxxvii Scherer, F. M. and D. Ross (1990), Industrial Market Structure and Economic Performance, Third Edition, Houghton Mifflin Company.

${ }^{x c v i}$ Katz, M. L. and C. Shapiro (1985), "Systems Competition and Network Effects," Journal of Economic Perspectives, 8(2), pp. 93-115.

xcvii Katz, M. L. and C. Shapiro (1986), "Product Compatibility Choice in the Market with Technological Progress," Oxford Economic Papers Special Issues on the New Industry Economics, pp. 146-165

xcix Coase, R. (1937), "The nature of the Firm," Economica, 2(1), pp. 386-405. Repritned in Williamson and Winter (eds.)(1991).

c Coase, R. (1988), "The Nature of the Firm: Origin, Meaning, and Influence," Journal of Law, Economics and Organization. Repritned in Williamson and Winter (eds.) (1991).

ci Coase, R.(1992), "The Institutional Structure of Production,", American Economics Review, 82(4), pp. 713-719.

cii Williamson, O. E. (1975), Markets and Hierarchies, New York, Free Press.

ciii Williamson, O. E. (1996), The Mechanisms of Governance, Oxford University Press.

civ Grindley, P. (1995), Standards Strategy and Policy; Cases and Stories, Oxford University Press.

cv David, P. A. and S. M. Greenstein (1990), "The Economics of Compatibility Standards: An Introduction to Recent Research," Economics of Innovation and new Technology, 1(1), pp. 3-41.

cvi Levi, M (2000), "When good defenses make good neighbors: a transaction cost approach to trust, the absence of trust and distrust," in C. Ménard (ed.), Institutions, Contracts and Organizations: Perspectives from New Institutional Economics, Edward Elgar, pp. 137-157.

cvii Williamson, O. E. (1981), "The modern corporation; Origins, evolution, attributes," Journal of Economic Literature, 19, pp. 1537-1568.

cviii Panzar, J. C. and R. D. Willig (1981), "Economies of Scope," American Economic Review, May, pp. 268-272.

cix McClelland and Rumelhart (1995), Parallel Distributed Processing, MIT Press.

cx Pinker, S. (1997), How the Mind Works, Norton.

cxi Fodor, J. (2000), The Mind Doesn't Work That Way, MIT Press.

cxii Carruthers, P. (2004), "Practical Reasoning in a Modular Mind," Mind \& Language, 19(3), pp. 259-278.

cxiii Meyer, M. H. and A. P. Lehnerd (1997), The power of Product Platforms, The Free press

cxiv Robertson, D. and K. Ulrich (1998), "Planning for Product Platforms," Sloan Management Review, Summer, pp. 19-31. 